\title{
Post-Ugi Cyclization for the Construction of Diverse Heterocyclic Compounds: Recent Updates
}

\author{
Jitender Bariwal ${ }^{1}$, Rupinder Kaur ${ }^{2}$, Leonid G. Voskressensky ${ }^{3}$ and \\ Erik V. Van der Eycken ${ }^{3,4 *}$
}

${ }^{1}$ Shiva Institute of B. Pharmacy, Bilaspur, India, ${ }^{2}$ Department of Pharmaceutical Chemistry, ISF College of Pharmacy, Moga, India, ${ }^{3}$ Laboratory for Organic \& Microwave-Assisted Chemistry, University of Leuven, Leuven, Belgium, ${ }^{4}$ Peoples'

Friendship University of Russia (RUDN University), Moscow, Russia

\section{OPEN ACCESS}

Edited by:

Andrea Basso,

Università di Genova, Italy

Reviewed by:

Valentine Nenajdenko,

Lomonosov Moscow State University,

Russia

Marta Meazza

University of Southampton,

United Kingdom

${ }^{*}$ Correspondence:

Erik V. Van der Eycken

erik.vandereycken@kuleuven.be

Specialty section

This article was submitted to

Organic Chemistry,

a section of the journal

Frontiers in Chemistry

Received: 25 July 2018 Accepted: 29 October 2018 Published: 20 November 2018

Citation:

Bariwal J, Kaur R, Voskressensky LG and Van der Eycken EV (2018)

Post-Ugi Cyclization for the Construction of Diverse Heterocyclic Compounds: Recent Updates.

Front. Chem. 6:557.

doi: 10.3389/fchem.2018.00557
Multicomponent reactions (MCRs) have proved as a valuable tool for organic and medicinal chemist because of their ability to introduce a large degree of chemical diversity in the product in a single step and with high atom economy. One of the dominant MCRs is the Ugi reaction, which involves the condensation of an aldehyde (or ketone), an amine, an isonitrile, and a carboxylic acid to afford an $\alpha$-acylamino carboxamide adduct. The desired Ugi-adducts may be constructed by careful selection of the building blocks, opening the door for desired post-Ugi modifications. In recent times, the post-Ugi transformation has proved an important synthetic protocol to provide a variety of heterocyclic compounds with diverse biological properties. In this review, we have discussed the significant advancements reported in the recent literature with the emphasis to highlight the concepts and synthetic applications of the derived products along with critical mechanistic aspects.

Keywords: Post-Ugi modifications, heterocycles, multicomponent reactions, MCR, post-Ugi cyclization

\section{INTRODUCTION}

Multicomponent reactions (MCRs) are considered as privileged one-pot processes involving a sequential combination of at least three reagents in the same pot (Ramon and Yus, 2005). The MCRs have found their usefulness and influence in Diversity-Oriented Synthesis (DOS) particularly in the field of medicinal chemistry (Biggs-Houck et al., 2010). The combinatorial compound libraries play a vital role for achieving the goal of DOS providing large compound libraries with reduced synthetic steps and with increased molecular complexity (Bariwal et al., 2010).

From the past two decades, the Ugi four-component reaction (Ugi-4CR) has offered one of the most investigated reaction route for generating multifunctional adducts, owing to the mildness of the reaction conditions, the wide application and the high variability (four diversity points) associated with it (Ugi and Steinbrückner, 1961; Ugi, 1962). More importantly, the Ugi-adduct can be manipulated by careful selection of the starting components (amine, acid, isonitrile, and aldehyde/ketone). Synthesis of the desired heterocycle can be achieved by performing a post-Ugi transformation on the exclusively designed Ugi-adduct (Sharma et al., 2015). The efficiency of postUgi transformation is further enhanced by manipulating the Ugi-adducts in a regioselective manner to provide access to complex heterocycles in a domino fashion (Li et al., 2016) (Scheme 1).

There are several reports for the transformations of the Ugi-adducts to diverse heterocyclic systems including Ugi-Heck, Ugi-ring opening metathesis, Ugi-intramolecular arylation, 


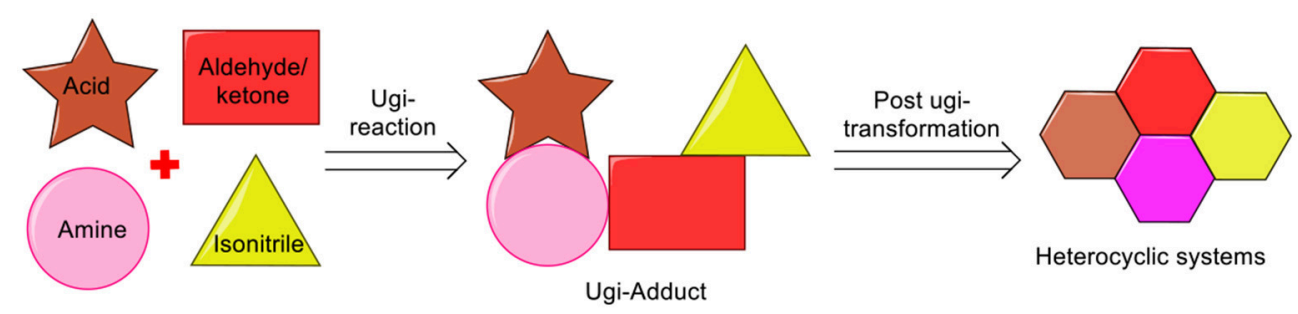

SCHEME 1 | Ugi multicomponent reaction and post Ugi transformation to heterocyclic system.

post-Ugi-cascades, and metal/ligand regio-, chemoselectivity switch, which has been reviewed by us recently (Sharma et al., 2015) and others (Hulme and Dietrich, 2009; Kaïm and Grimaud, 2010, 2014; Koopmanschap et al., 2014; Xiuming et al., 2017). During the last few years, noteworthy progress in the post-Ugitransformations has taken place as is evident from the substantial number of reports. We have carefully selected the prime literature reports where Ugi-adducts have been cyclized to generate a variety of heterocyclic systems. The present review mainly covers the literature reports on post-Ugi-modifications appeared after the year 2014. However, we have included few other important reports before the year 2014 and were not discussed in previous reviews. We have grouped these reports based on the structural complexity of the product after cyclization. For more clarity, we have started the discussion with the construction of the small heterocyclic systems to larger, and then followed by fused systems after post-Ugi-cyclization as given below:

1. Four-membered heterocycles

2. Five-membered heterocycles

3. Six-membered heterocycles

4. Fused heterocycles

4.1 Five-membered heterocycles fused with five-membered heterocyclic systems

4.2 Five-membered heterocycles fused with six-membered carbocyclic systems

4.3 Five-membered heterocycles fused with six-membered heterocyclic systems

4.4 Five-membered heterocycles fused with medium sized heterocyclic systems

4.5 Six-membered heterocycles fused with six-membered carbocyclic systems

4.6 Seven-membered heterocycles fused with six-membered carbocyclic systems

4.7 Nine-membered heterocycles fused with five-membered heterocycles

5. Tricyclic fused heterocycles

6. Spiro-polyheterocycles

\section{FOUR-MEMBERED HETEROCYCLES}

2-Azetidinones, known as $\beta$-lactams, are well known antimicrobial agents and are important synthetic intermediates for vitamins, alkaloids, and $\beta$-amino acids. Van der Eycken et al. (Li et al., 2015b) have developed a diversity-oriented post-Ugi intramolecular cyclization of Ugi-adducts $2 \mathbf{a}$ to give access to $\alpha$-methylene $\beta$-lactams $\mathbf{2 b}$ in moderate to excellent yields using $\mathrm{InCl}_{3}$ as a catalyst in toluene at $120^{\circ} \mathrm{C}$ with $\alpha, \beta$-unsaturated $\gamma$-lactams 2c as a minor product (Scheme 2). Under the optimized conditions, the intramolecular cyclization reaction proceeded smoothly to give $\alpha$-methylene $\beta$-lactams utilizing a variety of substituents on the Ugi-adducts. Ugi-adducts (2d and 2e) prepared from 1-trityl- $1 H$-imidazole-4-carbaldehyde and 4-methylthiazole-2-carbaldehyde provided the corresponding alkylidene- $\beta$-lactams $2 \mathbf{f}$ in good yields. However, Ugi-adduct derived from imidazo[1,2-a]pyridine-3-carbaldehyde or from benzaldehyde failed to cyclized under these conditions. Moreover, the use of Ugi-adducts derived from 4-pentynoic acid did not provide the desired alkylidene- $\beta$-lactam.

Interestingly, switching the catalyst to $\mathrm{AlCl}_{3}$, provided exclusive access to the unsaturated $\gamma$-lactams $\mathbf{2 g}$ in moderate to excellent yields. Under the optimized conditions, the Ugi-adducts obtained from substituted imidazo[1,2a]pyridine-2-carbaldehydes provided moderate to good yields, whereas 1-trityl-1H-imidazole-4-carbaldehyde derived Ugi-adduct provided a low product yield (20\% only). In addition, Ugi-adducts 2 a prepared from imidazo[1,2a]pyridine-2-carbaldehyde and 2-butynoic acid, underwent the $\mathrm{InCl}_{3}$-catalyzed Michael addition reaction $\left(\mathrm{InCl}_{3}(10 \mathrm{~mol} \%)\right.$ in DCE at $120^{\circ} \mathrm{C}$ for $12 \mathrm{~h}$ ) and provided exclusive access to $\gamma$-lactam $2 \mathbf{h}$ in good to excellent yields, even with a bulky substituent such as a phenyl group on the alkyne.

\section{FIVE-MEMBERED HETEROCYCLES}

Shiri et al. (2014) have reported a selective synthesis for a series of novel indolyl based $\gamma$-lactams $\mathbf{3} \mathbf{b}$ by cyclization of Ugiadducts $3 \mathbf{a}$ in the presence of $\mathrm{K}_{2} \mathrm{CO}_{3}$ in $\mathrm{DMF}$ at $100^{\circ} \mathrm{C}$ within few hours (Scheme 2). Under the optimum conditions, adducts derived from activated anilines underwent the reaction smoothly and gave access to the corresponding lactams in moderate to good yields. However, synthesis of Ugi-adducts using deactivated anilines met with failure. Benzyl aniline derived Ugi-adduct also afforded the desired $N$-benzyl lactam in excellent yield, whereas benzaldehyde-derived Ugi-adduct required modified conditions (KOH (1.0 equiv) $\mathrm{DMF}, 100^{\circ} \mathrm{C}, 10 \mathrm{~h}$ ) to provide access to the $\gamma$-lactam in moderate yield. Bulky tert-butyl isocyanide-derived 


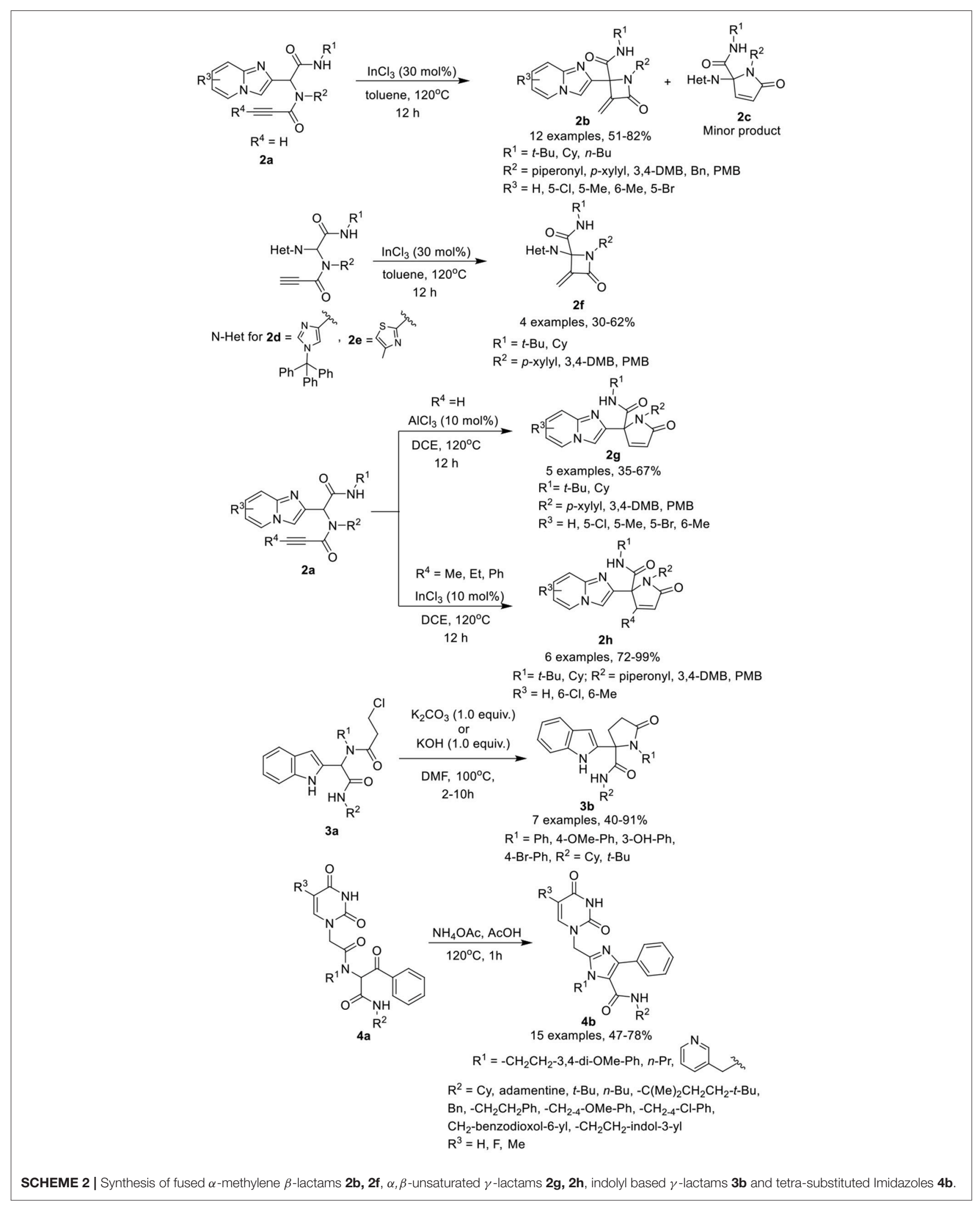


Ugi-adduct significantly reduced the product yield compared to the cyclohexyl substituted substrate.

Dömling et al. (Madhavachary et al., 2018) have developed a new, facile one-pot synthetic approach for the synthesis of uracil/thymine-containing tetra-substituted imidazoles $\mathbf{4 b}$ by cyclizing Ugi-adducts 4 a with $\mathrm{NH}_{4} \mathrm{OAc}$ in $\mathrm{AcOH}$ at $120^{\circ} \mathrm{C}$ in moderate to excellent yields (Scheme 2). Under the optimized conditions, a variety of substituted isocyanides, aliphatic, and aromatic amines and uracil derived acetic acids were found suitable for the reaction and provided good to excellent product yields. From this small library, products obtained from 5fluorouracil and 5-methyluracil acetic acids are interesting analogs of the marketed drugs Retrovir and Tegafur and were obtained in only two synthetic steps.

\section{SIX-MEMBERED HETEROCYCLES}

Balalaie et al. (2017a) have developed a facile postUgi-transformation to cyclize Ugi-adducts $\mathbf{5 a}$ to 2,5diketopiperazines $\mathbf{5 b}$ in good to excellent yields in the presence of triphenylphosphine as catalyst in ethanol at $80^{\circ} \mathrm{C}$ (Scheme 3). Under the optimized conditions, various Ugi-adducts derived from aldehydes and anilines bearing electron-withdrawing and electron-releasing substituents performed well to give the desired products in good to high yields, except with thiophene-2-carbaldehyde and 2-iodo substituted aniline which were obtained in moderate yields. Adducts derived from isocyanides bearing cyclohexyl or ethyl ester underwent the reaction smoothly. However, with tert-butyl bearing isocyanide, acetonitrile as solvent was required to furnish the corresponding 2,5-diketopiperazines in moderate yields. The post-Ugi cyclization reaction proceeds by nucleophilic addition of triphenylphosphine to the active alkyne group followed by the proton transfer from amide $\mathrm{NH}$ as shown in $[\mathbf{A}]$. The nucleophilic addition of nitrogen results in the formation of cyclized intermediate [B], followed by $\mathrm{PPh}_{3}$ elimination furnishing the desired 2,5-diketopiperazines $\mathbf{5 b}$.

Halimehjani and Sharifi (2017) have reported a simple approach to synthesize functionalized piperazine 2,5-diones $\mathbf{6 b}$ via intramolecular aza-Michael addition reaction of Ugi-adducts 6a in the presence of $\mathrm{NaH}$ in THF at $\mathrm{rt}$ (Scheme 3). Under the optimized conditions, the reaction proceeds smoothly and provides high product yields with excellent diastereoselectivity.

\section{FUSED HETEROCYCLES}

\section{Five-Membered Heterocycles Fused With Five-Membered Heterocyclic Systems}

Li et al. (He et al., 2017) have developed a facile post-Ugi gold(I)-catalyzed domino dearomatization/ipso-cyclization/azaMichael cascade reaction of diverse Ugi-adducts $7 \mathbf{a}$ to gain access to the functionalized tetracyclic benzo[e]pyrrolo[2,3c] indole-2,4,7(5H)-triones $\mathbf{7 b}$ in good yields and with unique diastereoselectivities. The reaction gave best results when $\mathrm{Au}\left(\mathrm{PPh}_{3}\right) \mathrm{OTf}$ was used as a catalyst in $\mathrm{CHCl}_{3}$ at $70^{\circ} \mathrm{C}$ (Scheme 4). Under the optimized conditions, a variety of
Ugi-adducts 7a prepared from diversely substituted amines, isocyanides and acids bearing electron-withdrawing or electrondonating groups performed well to give the desired products in good to excellent yields. Interestingly, Ugi-adducts derived from isonitriles bearing a bulky substituent did not significantly affected the reaction yield. The substrates comprising a terminal alkyne also gave the exo-dig products in moderate to good yields. The gold(I)-catalyzed domino dearomatization/ipsocyclization/aza-Michael sequence proceeded by in situ formation of a cationic gold(I) species which is followed by nucleophilic attack by the C-4 position of the 1-naphthol (5-exo-dig fashion) as shown in intermediate $[\mathbf{A}]$. This leads to the formation of the spirocarbocyclic intermediate [B]. This generated the tetracyclic scaffold via aza-Michael addition facilitated by $\pi$-activation by the cationic gold species.

\section{Five-Membered Heterocycles Fused With Six-Membered Carbocyclic Systems}

Sharada et al. (Sagar et al., 2015) have described a $\mathrm{FeCl}_{3}$ catalyzed post-Ugi cyclization protocol for cyclization of $\alpha$ amino amidines 8a, generated via an Ugi-3CR using silica gel as promoter, to construct amidino substituted indazoles $\mathbf{8 b}$ in good to high yields in DMF at $120^{\circ} \mathrm{C}$ (Scheme 4). Under the optimized conditions, a variety of amidino substituted indazoles were prepared where the electronic nature of substituents on the various Ugi-components did not hamper the reaction and provided good product yields.

Van der Eycken et al. (Ambasana et al., 2014) have reported a solvent switchable metal-free $[4+2]$ cycloaddition reaction via $\mathrm{C}_{\mathrm{sp}}^{2}-\mathrm{H}$ functionalization of the Ugi-adduct, $N$-propynylphenyl propiolamide $9 f$ (prepared by reacting aldehyde $\mathbf{9 a}$, amine $\mathbf{9 b}, \mathbf{2 -}$ alkynoic acid 9c and isonitrile 9d), to access the $N$-substituted benzo[f]isoindolone $\mathbf{9 e}$ or benzo[e]isoindolone $\mathbf{9 g}$ in excellent yields and with good regioselectivity. The cyclization reaction to access the benzo[e]isoindolones $\mathbf{9} \mathrm{g}$ gave best results in toluene at $150^{\circ} \mathrm{C}$. However, the use of a polar-protic solvent alone, or with toluene as co-solvent, resulted in an increased formation of benzo[f]isoindolone 9e. Interestingly, use of $n-\mathrm{BuOH}$ as a solvent in a one-pot reaction for Ugi-4CR and ring closure reaction, provided access to selective formation of $\mathbf{9 e}$ over 9g (Scheme 4). Under the optimized conditions, Ugi-adducts generated from a broad range of aromatic aldehydes, isonitriles and acids performed well to furnish the benzo[f]isoindolones $\mathbf{9 e}$ in excellent yields. However, a low yield of 9e was observed when aliphatic aldehyde- such as valeraldehyde- derived Ugiadducts were used in the reaction, whereas use of Ugi-adduct derived from phenyl propargylamine did not underwent the reaction. Further, variedly substituted benzo[e]isoindolones $\mathbf{9 g}$ were prepared in moderate to high yields under the optimized conditions from Ugi-adducts derived from differently substituted aldehydes, acids and isonitriles. Importantly, an electronwithdrawing group on the acids improves the yields, while the use of an electron deficient aldehyde and electron rich acid provides low product yields. Interestingly, employing $o$-substituted acid derived Ugi-adduct under the optimized conditions led to the formation of product $\mathbf{9 g}$ as a single isomer. 


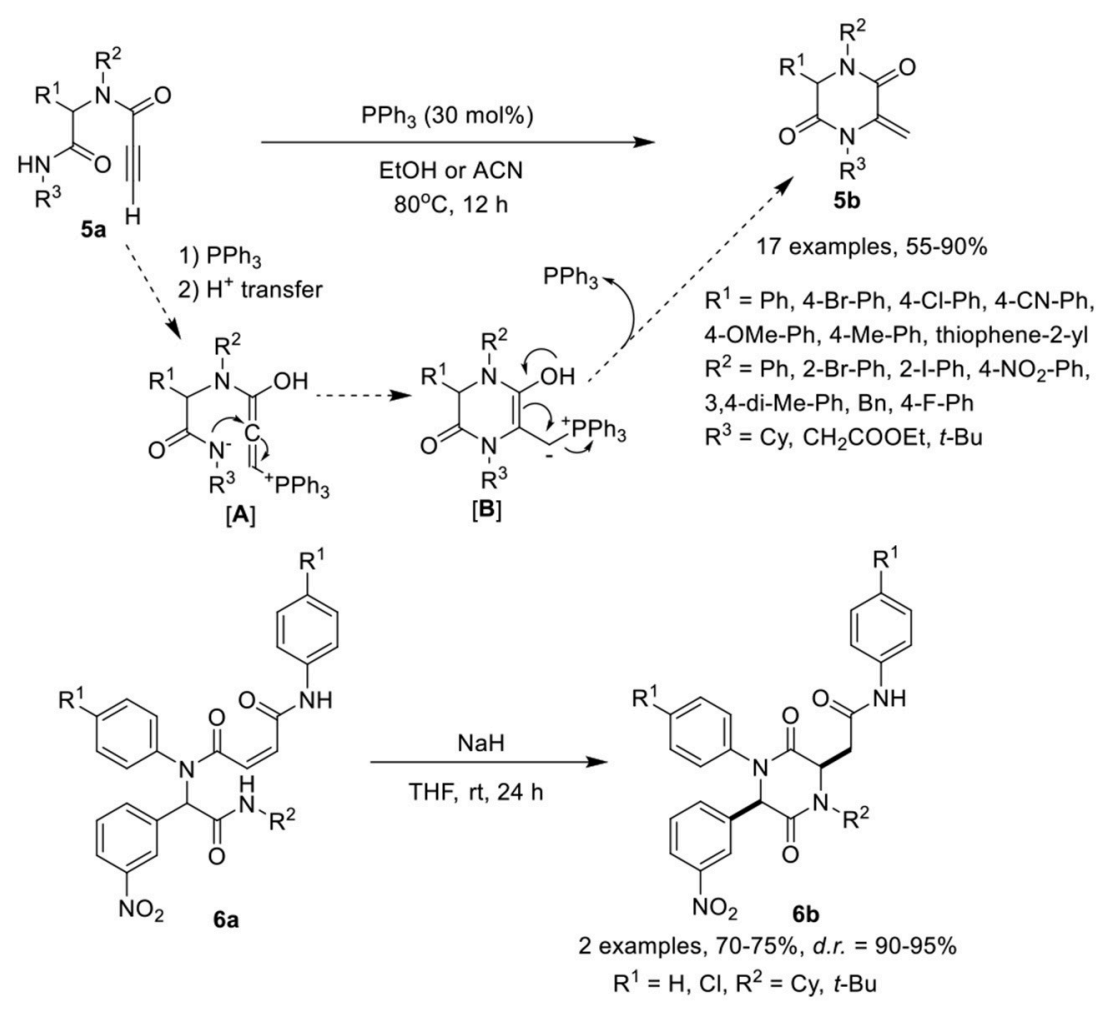

SCHEME 3 | Synthesis of arylidence 2,5-diketopiperazines $\mathbf{5 b}$ and piperazine 2,5-dione $\mathbf{6 b}$.

\section{Five-Membered Heterocycles Fused With Six-Membered Heterocyclic Systems}

González-Zamora et al. (Zamudio-Medina et al., 2015) have described a one-pot, Ugi-4CR for the synthesis of cyclic analogs of hexamethylenebis(3-pyridine)amide (HMBPA) 10e in low yields. After reaction of diamine 10a, aldehydes 10b, and isocyanoacetamides 10c, cycloaddition and ring opening reaction with maleic anhydride 10d was performed under MW irradiation using $\mathrm{Sc}(\mathrm{OTf})_{3}$ as a catalyst in benzene (Scheme 5). Under the optimized conditions, different isocyanoacetamides and aldehydes furnished the corresponding products 10e in low yields. During this one-pot synthetic operation, six new chemical bonds were formed.

Van der Eycken et al. (Li et al., 2015a) have developed a facile catalyst-controlled regioselective process for post-Ugi intramolecular hydroarylation reaction to provide access to heterocycles such as pyrroloazepinones $\mathbf{1 1} \mathbf{b}$, pyrrolopyridinones 11c, and benzothienopyridines 11d in high yields. The intramolecular hydroarylation of Ugi-adduct 11a furnished the desired pyrroloazepinone $\mathbf{1 1 b}$ and pyrrolopyridinone $11 \mathrm{c}$ in a nearly 1:1 ratio when $\mathrm{Au}\left(\mathrm{PPh}_{3}\right) \mathrm{Cl}$ and AgOTf were used as a catalytic system at $50^{\circ} \mathrm{C}$ in $\mathrm{CDCl}_{3}$. Switching the catalyst to $\mathrm{AgSbF}_{6}$ in $\mathrm{CDCl}_{3}$ at $70^{\circ} \mathrm{C}$ provided exclusive access to pyrroloazepinones $\mathbf{1 1 b}$ in excellent yields (Scheme 5). Other silver and gold salts such as $\mathrm{AgOTf}, \mathrm{AgBF}_{4}, \mathrm{AgNTf}_{2}, \mathrm{AuCl}_{3}$, or $\mathrm{AuCl}$ also provided product in moderate to good yield. Interestingly, the use of $\mathrm{InCl}_{3}$ as catalyst in $\mathrm{CDCl}_{3}$, resulted in a switch of selectivity and afforded the pyrrolopyridinones 11c in excellent yields. Ugi-adducts prepared from aliphatic $n$ butylamine or bulky alkyne substituents, such as phenyl, were not found suitable under these conditions resulting in unstable pyrrolopyridinones. On the other hand, for the pyrroloazepinone 11b, diversely substituted Ugi-adducts performed well and provided good product yields. However, a bulky phenyl substituent on the alkyne, resulted in a drastic reduction of the product yield, whereas a terminal alkyne afforded the corresponding product in moderate yields. An electrondonating substituent on the carboxamide moiety provided excellent product yields in both cases. In addition, the exo-dig cyclization of the benzothiophene comprised Ugi-adducts was also performed in the presence of IPrAuNTf 2 as catalyst in DCE at $70^{\circ} \mathrm{C}$, affording the selective benzothienopyridines $11 \mathbf{d}$ in excellent yields, whereas $\mathrm{Au}\left(\mathrm{PPh}_{3}\right) \mathrm{OTf}$ provided the products in moderate yield and $\mathrm{InCl}_{3}, \mathrm{AgSbF}_{6}$, or $\mathrm{AuCl}_{3}$ did not work for this conversion. Under the optimized conditions, a variety of Ugi-adducts obtained from acids and isonitriles were well tolerated. However, a bulky phenyl substituent on the alkyne failed to give the corresponding product, whereas electrondonating substituents on the amines proved beneficial in this reaction.

Peshkov et al. (Trang et al., 2015) have developed a onepot base-promoted post-Ugi carbocyclization of Ugi-adduct 12a with cleavage of the isocyanide-originated amide moiety, to provide facile access to 6,7-dihydro-5 $\mathrm{H}$-pyrrolo[3,4- $b$ ]pyridin-5ones $\mathbf{1 2} \mathbf{b}$ in high yields when performed under inert atmosphere at $110^{\circ} \mathrm{C}$ in DMF. However, when this reaction was performed 

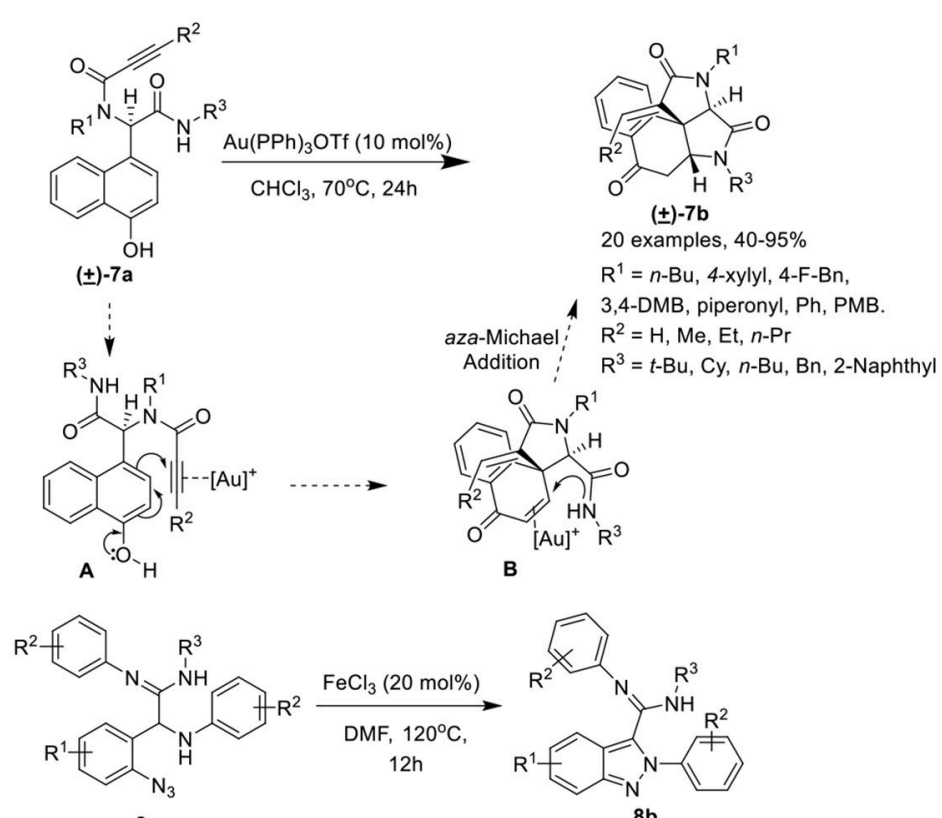

$8 a$

$8 b$

10 examples, $58-75 \%$

$\mathrm{R}^{1}=\mathrm{H}, 4-\mathrm{Br}, 5-\mathrm{Br} \mathrm{R}^{2}=$ 2,4-diMe, 2-Br, 4-Br,

2-Br-4-Me, 2-F, 4-F; $\mathrm{R}^{3}=t-\mathrm{Bu}, \mathrm{Cy}$

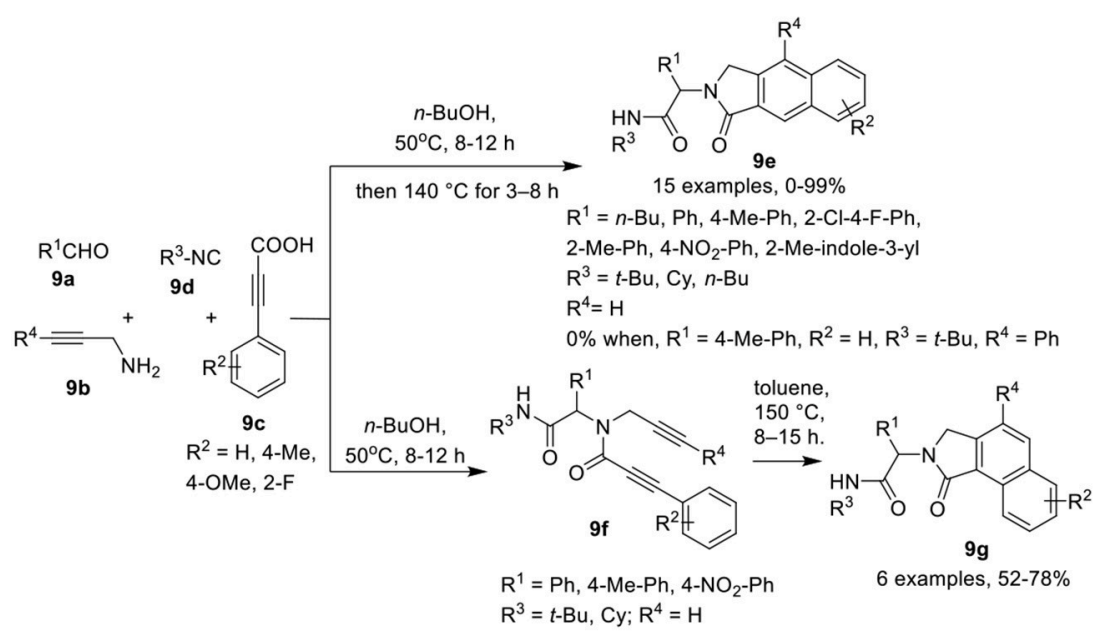

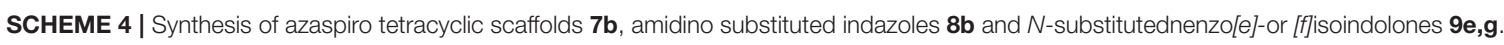

under air atmosphere, the oxidized 7-hydroxy-6,7-dihydro$5 H$-pyrrolo[3,4-b]pyridin-5-one 12c was obtained (Scheme 6). Adducts derived from a diverse array of aromatic amines as well as several aromatic and heteroaromatic aldehydes were found suitable in both inert and aerobic conditions, provided the desired products in good to moderate yields. However, aliphatic amines drastically reduced the product yield for both normal $\mathbf{1 2 b}$ and oxidized product 12c. Interestingly, the use of butylamine resulted in a poor yield of normal product $\mathbf{1 2 b}$ and failed to give the oxidized product $12 \mathrm{c}$. In general, the yields for the nonoxidized products $\mathbf{1 2 b}$ were higher than for the oxidized ones 12c.
Srivastava et al. (Ghoshal et al., 2017) have reported an efficient and divergent one-pot sequential Ugi-4CR of amino acetaldehyde acetals $13 \mathbf{a}$, ketone $\mathbf{1 3 b}$ or aldehydes $13 \mathrm{c}$, alkynoic acids 13d, and isocyanides $\mathbf{1 3} \mathbf{e}$ in ethanol and subsequent acid-mediated Povarov-type reaction followed by treatment with substituted anilines $\mathbf{1 3 f}$ and $\mathrm{H}_{2} \mathrm{SO}_{4}$ to afford the fused quinolines $13 \mathrm{~g}$, and $13 \mathrm{~h}$ in moderate to excellent yields at $\mathrm{rt}$ (Scheme 6). Under the optimized conditions, a diverse array of anilines bearing electron-rich as well as electron-deficient substituents were well tolerated in the Povarov-type reaction. However, heteroaromatic amines afforded the corresponding product in low yield. Interestingly, electron-deficient anilines 

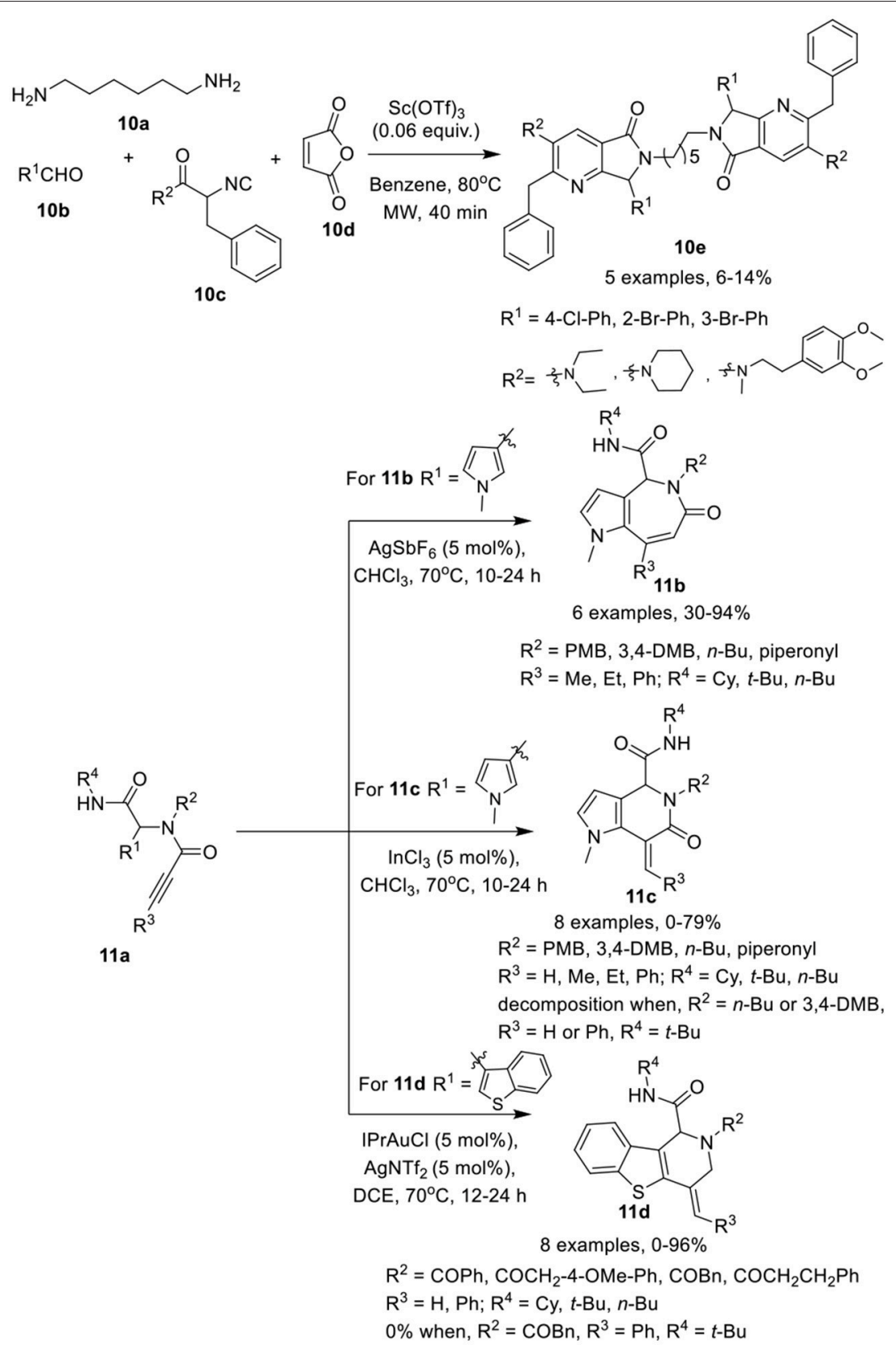

SCHEME 5 | Synthesis of cyclic analogs of HMBPA 10e, pyrroloazepinones 11b, pyrroloazepinones 11c, and benzothienopyridines 11d.

such as 2-iodo-4-nitroaniline provided dihydro-2,3-dihydro$1 H$-pyrrolo[3,4-b]quinolin-1-ones (DHPQ) as a minor product which after oxidation, afforded the desired product in low yield. Among the isocyanides, tert-butylisocyanide and cyclohexylisocyanide were suitable, whereas the use of naphthylisocyanide led to the formation of the desired product in poor yield. For the acid counterpart, phenylpropiolic acid and other alkynoic acids were found suitable in the reaction resulting in good product yields. A diverse array of aromatic aldehydes bearing electron-rich or electron-deficient groups, as well as, aliphatic aldehydes were found suitable in this reaction, affording the corresponding products in moderate to excellent yields. Importantly, the acidic proton in the Ugi-adduct did not interfere in the Povarov-type reaction. Under these conditions, unprotected propiolamides also provided access to the corresponding products via Povarov-type reaction in moderate yields.

Van der Eycken et al. (He et al., 2018) have developed an efficient gold(I)-catalyzed post-Ugi domino dearo matization/ipso-cyclization/Michael sequence of Ugi-adduct 


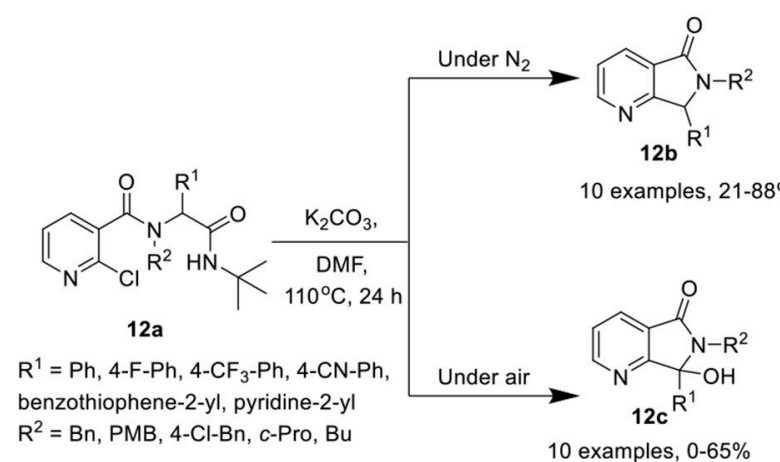
$\mathrm{R}^{2}=\mathrm{Bn}, \mathrm{PMB}, 4-\mathrm{Cl}-\mathrm{Bn}, c-$ Pro, Bu

\section{0 examples, 0-65\%}

$0 \%$ when, $\mathrm{R}^{1}=\mathrm{Ph}, \mathrm{R}^{2}=\mathrm{Bu}$
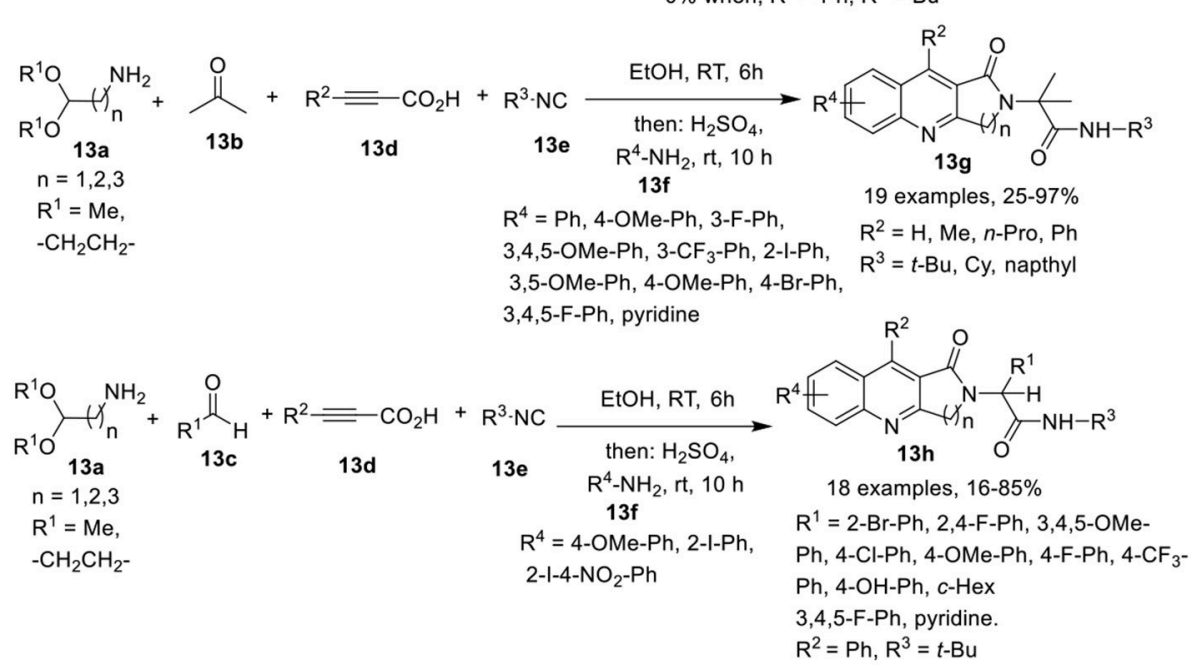

SCHEME 6 | Synthesis of 6,7-dihydro-5H-pyrrolo[3,4-b]pyridine-5-ones $\mathbf{1 2} \mathbf{b}$ and the oxidized product $\mathbf{1 2 c}$ and fused quinolones $\mathbf{1 3} \mathbf{g}$ and $\mathbf{1 3 \mathbf { h }}$.

14a that provided access to various (hetero)-arene-annulated tricyclic heterocycles 14b in moderate to good yields with excellent chemo-, regio-, and diastereoselectivity. The reaction for the synthesis of indole-annulated tricyclic heterocycle 14b proceeded smoothly utilizing IPrAuCl and AgOTf as catalytic system in $\mathrm{CDCl}_{3}$ at $\mathrm{rt}$ (Scheme 7). Under the optimal conditions, Ugi-adducts derived from aliphatic and aromatic isonitriles underwent the reaction smoothly and provided good product yields. Bulky alkyne substrates provided good product yields, whereas Ugi-adducts bearing a terminal alkyne did not performed well. Electron-donating as well as electronwithdrawing substituents on the indole ring were well tolerated and provided high yields. A strong electron-withdrawing benzenesulfonyl group on the indole nitrogen atom drastically reduced the $\mathrm{C} 3$ nucleophilicity, resulting in the need of high temperature $\left(115^{\circ} \mathrm{C}\right)$ to perform the reaction in excellent yield. In contrast to Ugi-adducts derived from ortho-substituted 4-aminophenols, meta-substituted 4-aminophenols afforded low yields. Pyrrole-containing Ugi-adducts 15a gave access to the corresponding pyrrole-fused polyheterocycles $\mathbf{1 5 b}$ in good yields under the optimized conditions. In addition, different Ugi-adducts derived from various heteroaromatic aldehydes led to diverse (hetero)-arene-annulated tricyclic heterocycles in moderate to good yields using the modified conditions. The use of Ugi-adducts derived from benzofuran2-carbaldehyde, 1-phenyl-1H-pyrazole-5-carboxaldehyde, and benzo[b]thiophene-3-carbaldehyde resulted in the formation of a mixture of heteroarene-annulated tricycle $15 \mathrm{c}$ and spirocarbocyclic product $15 \mathrm{~d}$ in moderate to good yields upon heating at $115^{\circ} \mathrm{C}$. Furthermore, Ugi-adducts derived from electron-rich aromatic aldehydes (hydroxyand alkoxy-substituted benzaldehydes) when used in this domino process underwent the reaction smoothly in $\mathrm{CHCl}_{3}$ at $70^{\circ} \mathrm{C}$ to afford the benzene-annulated tricyclic heterocycles 15e in moderate to good yields. The pyrrolidine-substituted benzene provided the benzene-annulated tricycle in high yield at rt, whereas, piperidine- or morpholine-substituted benzaldehydes afforded the benzene-annulated tricycles $\mathbf{1 5 f}$ in DCE at $115^{\circ} \mathrm{C}$ in low yields. Interestingly, when these reactions were performed at $\mathrm{rt}$, only the spirocarbocyclic products were obtained (Scheme 7). The reaction proceeds by in situ generation of cationic gold(I) species that $\pi$-activates the alkyne group in the Ugi-adducts to give intermediate [A], which is subsequently attacked by the nucleophilic phenol in a 5-endo-dig fashion to afford spirocarbocyclic intermediate [B]. Subsequent Michael addition of the intermediate 
cyclohexadienone with the $\mathrm{C} 3$ position of the indole, results in the formation of the indole-annulated tricyclic heterocycle $\mathbf{1 4 b}$ (Scheme 7).

Krasavin et al. (Golubev and Krasavin, 2017) have developed an efficient synthetic protocol to access sterically encumbered tricyclic peptidomimetics $\mathbf{1 6 b}$ via intramolecular nucleophilic substitution reaction of Joullie-Ugi-adduct 16a in the presence of $\mathrm{NaH}$ in $\mathrm{THF}$ at $50^{\circ} \mathrm{C}$ in good to excellent yields (Scheme 8). Under the optimized conditions, bulky substituents on the amide nitrogen such as tert-butyl or mesityl, did not affect the reaction and provided good product yields. The remaining substituents on the Joullie-Ugi-adducts 16a did not affect the reaction output significantly. These tricyclic peptidomimetics may be useful as small molecule-ligands for peptidergic biological targets, including G-protein coupled receptors.

VenkataPrasad et al. (VenkataPrasad et al., 2017) have developed an efficient and facile post-Ugi condensation approach to access the pyrrolo[2,3-c]pyridines $\mathbf{1 7 b}$ in excellent yields, using $50 \mathrm{~mol} \%$ PTSA in methanol at $50^{\circ} \mathrm{C}$ (Scheme 8). Under the optimized conditions, diversely substituted Ugiadducts $17 \mathbf{a}$ provided the desired products, in moderate to excellent yields. Use of Ugi-adducts bearing $\mathrm{CF}_{3}$ on the aniline or on the phenyl glyoxylic acid, provided the respective pyrrolo[2,3-c]pyridones in excellent yields. However, use of $\mathrm{NO}_{2}-$ substituted aniline did not provided the Ugi-adduct, whereas Ugi-adducts derived from phenylglyoxalic acid bearing a $\mathrm{NO}_{2}-$ group failed to cyclize under the optimized conditions. The reaction proceeds via protonation of $\alpha$-keto group of the Ugi-adduct, followed by the electrophilic addition on the pyrrole ring to give intermediate $[\mathbf{A}]$, which subsequently underwent dehydration to afford the desired compound via intermediate $[\mathbf{B}]$. This approach has many advantages including practical simplicity, high atom economy and short reaction time.

Sieburth et al. (Srinivasulu et al., 2018) have developed a serendipitous one-pot protocol for the diastereoselective construction of tricyclic chromenopyrroles $\mathbf{1 8 b}$ from Ugiadducts $18 \mathbf{a}$ in moderate to good yields, using $\mathrm{ZnBr}_{2}$ as catalyst in DCE under MW irradiation (Scheme 8). Under the optimized conditions, Ugi-adducts 18a derived from variously substituted methylamines and phenylacetic acids were found well tolerable and afforded the desired products in moderate to good yields. However, the use of benzylamine derived Ugi-adducts provided low product yields. Substitutions on the nitrogen of the Ugi-adduct have little effect on the product output and provided good product yields. Ugi-adducts derived from 2 -indole carboxylic acid also gave moderate product yields. Additionally, the Ugi-adducts prepared from $D$ - and $L$-phenylalanine and $L$ 3,4-dimethoxyphenylalanine underwent the reaction smoothly and furnished the corresponding products as a mixture of diastereomers in moderate yields, in spite of steric hindrance of the amine. The reaction proceeds through the coordination of $\mathrm{ZnBr}_{2}$ that catalyzes the $\mathrm{O}$-acylation by the tertiary amide [A], followed by rearrangement of the resultant tetrahedral intermediate $[\mathbf{B}]$. Abstraction of the benzylic proton led to the formation of azomethine ylide [C]. Subsequent intramolecular [3 $+2]$-cyclization delivered the highly strained intermediate [D], which undergoes expulsion of carbon dioxide and 1,4-proton migration to give the desired chromenopyrrole $\mathbf{1 8 b}$.

\section{Five-Membered Heterocycles Fused With Medium-Sized Heterocyclic Systems}

Van der Eycken et al. (Li et al., 2014b) have developed an efficient copper-catalyzed post-Ugi intramolecular Ullmann-coupling strategy to give access to $4 H$-benzo[f]imidazo[1,4]diazepin-6ones $19 \mathbf{b}$ in moderate to good yields using $\mathrm{Cs}_{2} \mathrm{CO}_{3}$ as a base in DMSO at $100^{\circ} \mathrm{C}$ under MW irradiation (Scheme 9). Under the optimized conditions, Ugi-adducts 19a derived from diversely substituted aromatic acids and amines were found suitable for this reaction and gave access to the corresponding products in moderate to high yields. Use of Ugi-adducts obtained from C-2 or C-5 substituted imidazole-4-carbaldehyde did not underwent the reaction and resulted in the decomposition of the starting Ugi-adduct, whereas Ugi-adducts assembled from imidazole-2-carbaldehyde furnished the corresponding products in moderate to high yields. The reaction takes place through the formation of intermediate [A] via coordination of copper(I) iodine with the amine of the Ugi-adduct 19a, which subsequently inserts into the aryl iodine bond, followed by reductive elimination of the resultant intermediate [B] generating $4 H$-benzo[f]imidazo[1,4]diazepin-6-one 19b.

Modha et al. (Vachhani et al., 2015) have developed a post-Ugi regioselective intramolecular carbocyclization approach to afford diversely substituted indoloazepinones $\mathbf{2 0 b}$ and indoloazocinones $\mathbf{2 0 d}$ in good to excellent yields, using $\mathrm{Au}\left(\mathrm{PPh}_{3}\right) \mathrm{SbF}_{6}$ as catalyst in $\mathrm{CDCl}_{3}$ at $50^{\circ} \mathrm{C}$ (Scheme 9). Under the optimized conditions, endo-dig cyclization afforded the indoloazepinones $\mathbf{2 0 b}$ in good to excellent yields. Ugiadducts 20a derived from aliphatic or aromatic aldehydes were well tolerated. Similarly, bulky substituents on the alkyne such as ethyl, isopropyl, and aryl underwent the reaction smoothly. However, the Ugi-adduct derived from a tertbutyl substituted alkyne, failed to afford the corresponding cyclized product. Interestingly, the Ugi-adduct derived from a terminal alkyne, provided the 6-exo-dig product. Additionally, intramolecular hydroarylation of Ugi-adducts 20c under the optimized conditions afforded the indoloazocinones 20d in good yields except the tert-butyl substituted alkyne. The regioselective intramolecular carbocyclization reaction was believed to progress through $\pi$-coordination of the cationic gold with the alkyne $[\mathbf{A}]$, followed by nucleophilic attack by the 3-position of the indole on the $\pi$-activated internal alkyne, in an endo-dig fashion, in contrast to the terminal alkyne (exo-dig fashion). Intermediate [B] was formed, which subsequently underwent a 1,2-shift and after deprotonation and protodeauration led to the formation of the indoloazepinone.

Hulme et al. (Medda et al., 2015) have developed a facile and concise route for post-condensation modifications of Ugiazide adducts 21 a to give the imidazotetrazolodiazepinones $\mathbf{2 1 d}$ in modest to excellent yields. The reaction proceeds by treatment of tetrazole $\mathbf{2 1 a}$ with an excess of isocyanate $\mathbf{2 1} \mathbf{b}$ in ethanol at $\mathrm{rt}$, followed by ring closure of the resultant hydantoin 21c with TFA in DCE under MW irradiation at $150^{\circ} \mathrm{C}$, furnishing the 

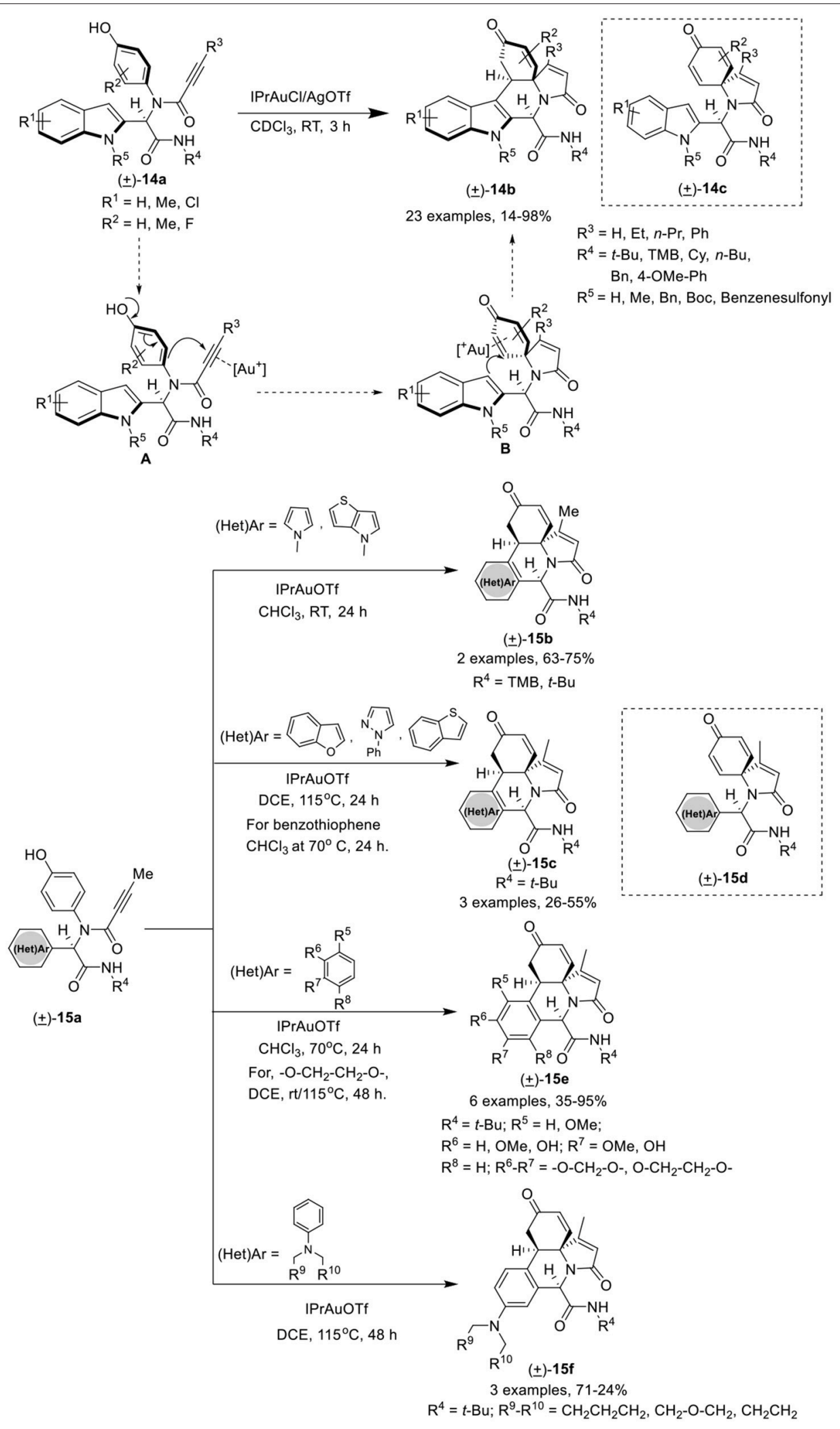

SCHEME 7 | Synthesis of indole-annulated tricyclic heterocycle 14b and diverse (hetero)-arene-annulated tricyclic heterocycle 15b-f. 


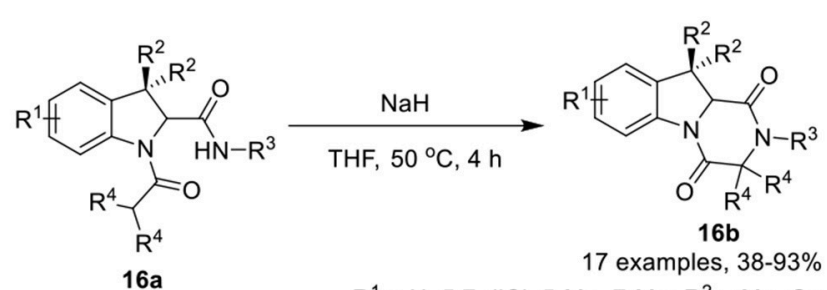

16a 17 examples, 38-93\%

$\mathrm{R}^{1}=\mathrm{H}, 5,7-\mathrm{diCl}, 5-\mathrm{Me}, 7-\mathrm{Me} ; \mathrm{R}^{2}=\mathrm{Me}, \mathrm{Cy},\left(\mathrm{CH}_{2} \mathrm{CH}_{2}\right)_{2} \mathrm{NSO}_{2} \mathrm{Me}$.

$\mathrm{R}^{3}=\mathrm{Bn}, \mathrm{Cy}, t-\mathrm{Bu}, 2,4,6-\mathrm{MePh}, \mathrm{PMB} ; \mathrm{R}^{4}=\mathrm{H}, \mathrm{Me}$<smiles>[R]NC(=O)C(c1ccc[nH]1)N(C(=O)C(C)(C)c1ccc([R])cc1)c1ccc([R7])c([R])c1[R]</smiles>

A

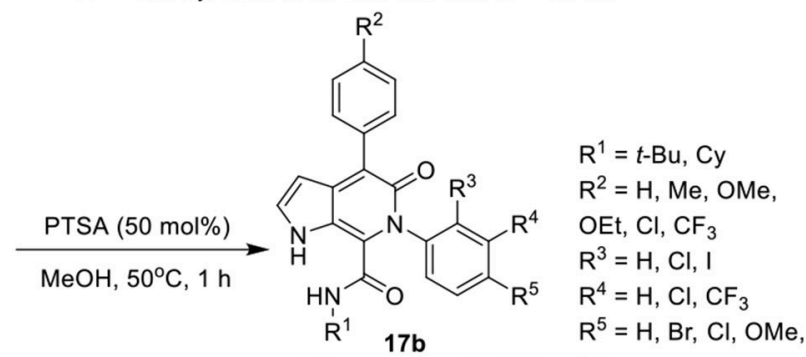

26 examples, $80-98 \% \quad \mathrm{Me}$<smiles>[R1]NC(=O)C1=C2NC=CC2(c2ccc([R2])cc2)C(O)(c2ccc([R])cc2)C1=O</smiles>

B<smiles>[R]CC1=C(C(C)=O)[C@H]2COc3ccccc3[C@H]2N1[R]</smiles>

$\mathrm{ZnBr}_{2}$ (30 mol\%)

DCE, $M W, 170^{\circ} \mathrm{C}, 30 \mathrm{~min}$

13 examples, $25-70 \%$

$\mathrm{R}^{1}=4-\mathrm{Me}-\mathrm{Ph}, 3,4,5-$ tri-F-Ph, 2-Br-Ph,

$\mathrm{N}$-Me-indol-2yl, $\mathrm{CH}_{2} \mathrm{CH}_{2} \mathrm{CO}_{2} \mathrm{Me}$

$\mathrm{R}^{2}=\mathrm{CH}_{2}$-furan-2-yl, $\mathrm{CH}_{2}$-thiophene-2-yl, $\mathrm{CH}_{2}-3,5$, diOMe-Ph, $\mathrm{CH}_{2}-3-\mathrm{Cl}-\mathrm{Ph}, \mathrm{Bn}$, $\mathrm{CH}_{2} \mathrm{CH}_{2}-3-\mathrm{OMe}-\mathrm{Ph}$ etc.

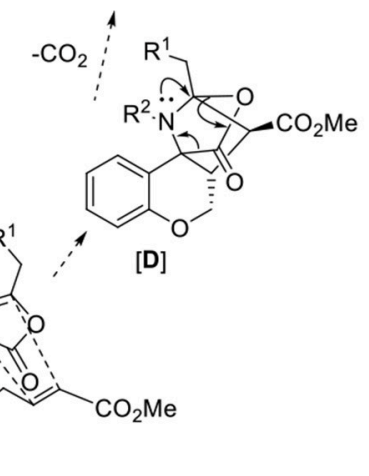

SCHEME 8 | Synthesis of substituted tetrahydropyrazino[1,2-a]indole-1,4-diones $\mathbf{1 6 b}$, pyrrolo[2,3-c]pyridines $\mathbf{1 7 b}$ and tricyclic chromenopyrroles $\mathbf{1 8 b}$. 


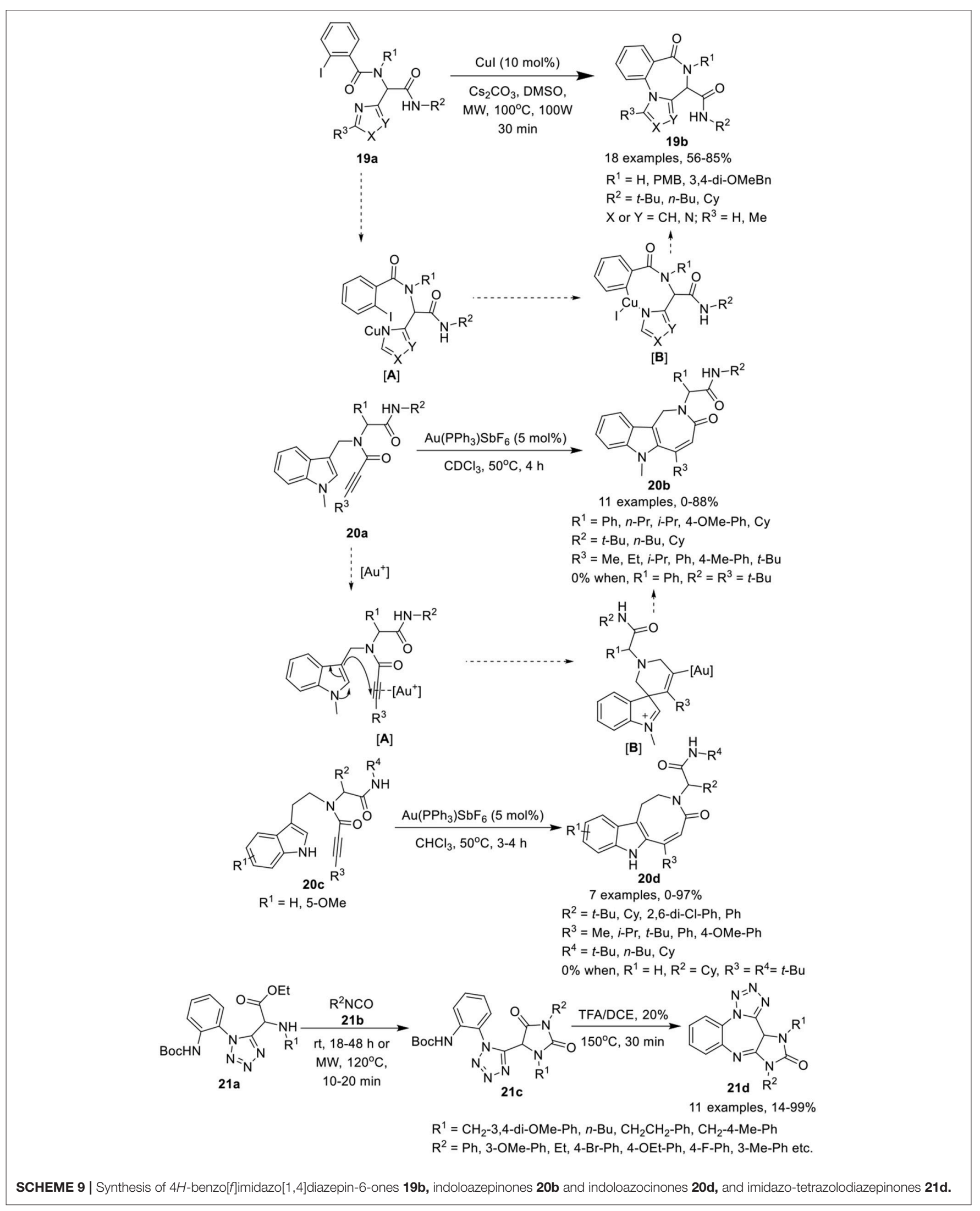


desired imidazotetrazolodiazepinones 21d (Scheme 9). Under the optimized conditions, diversely substituted Ugi-azide adducts 21a afforded the hydantoin products $21 \mathrm{c}$ in modest to high yields. Adducts derived from isocyanates bearing a 3-methoxyphenyl or an ethyl substituent yielded the desired hydantoin under MW irradiation at a slightly lower temperature of $120^{\circ} \mathrm{C}$. Ugi-adducts bearing aliphatic substituents were well tolerated, affording the desired products in higher yields compared to adducts with aromatic substituents. Ring closure and acid-mediated Bocremoval proceeded smoothly under MW irradiation to afford the corresponding products in modest to excellent yields.

Balalaie et al. (Balalaie et al., 2017b) have reported a diversity-oriented access to isoxazolino-benzazepines $\mathbf{2 2} \mathbf{b}$ and

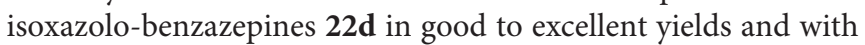
high diastereoselectivities $(\approx 95)$ via post-Ugi heteroannulation reaction involving intramolecular 1,3-dipolar cycloaddition of 2((hydroxyimino)methyl)benzoic acid 22a and 22c, respectively. The nitrile oxide reacted with alkenes or alkynes in the presence of sodium hypochlorite $(\mathrm{NaOCl})$ in DCM at rt (Scheme 10). Under the optimized conditions, Ugi-adducts derived from aldehydes bearing electron-donating or electron-withdrawing groups provided isoxazolino- and isoxazolo-benzazepines in good to high yields and with high diastereoselectivities. The use of aliphatic aldehydes in both reactions provided low product yields. Ugi-adducts derived from bulky tert-butyl isonitriles provided reduced product yields compared to cyclohexyl isonitrile derivatives. The reaction takes place through the chlorination of the oxime group in the Ugi-adduct to chloroxime [A], followed by removal of the proton from $\mathrm{OH}$ by in situgenerated $\mathrm{NaOH}$, and loss of the chloride group resulting in the formation of nitrile oxide [B]. Subsequent intramolecular 1,3dipolar cycloaddition of nitrile oxide with the alkene or alkyne group afforded the corresponding product.

\section{Six-Membered Heterocycles Fused With Six-Membered Carbocyclic Systems}

Ding et al. (Wang et al., 2016) have developed a sequential Ugi condensation/Wittig reaction of phosphonium salt 23a to give access to 1,2-dihydroisoquinolines $23 \mathrm{c}$ in moderate yields in a one-pot fashion. Ugi-adducts $23 \mathbf{b}$ prepared from<smiles>[R17]NC(=O)C(c1ccccc1)N(CC=C)C(=O)c1ccccc1/C=N/O</smiles><smiles>[R]O[W]</smiles><smiles>[R]NC(=O)C(c1cccc[R]1[R])N1CC2CON=C2c2ccccc2C1=O</smiles>

11 examples, 66-86\%

$$
\begin{aligned}
& \mathrm{R}^{1}=\mathrm{Cy}, t-\mathrm{Bu} \\
& \mathrm{R}^{2}=i-\mathrm{Pr}, 4-\mathrm{F}, 4-\mathrm{Cl}, 4-\mathrm{Br}, 4-\mathrm{Me},
\end{aligned}
$$$$
\text { 4-OMe, 3- } \mathrm{NO}_{2} \text {, 4-Ph-Ph }
$$<smiles>[R10]CC(C)C(=O)NCC#CCN(C(=O)c1ccccc1/C=N/O)C(C(=O)N[R10])c1ccccc1</smiles><smiles>[R1]NC(=O)C(c1ccccc1)N1CC2=CO[N+]=C2c2ccccc2C1=O</smiles>

9 examples, $64-92 \%$<smiles>[R]NC(=O)C(c1ccccc1)N(CC#C)C(=O)c1ccccc1/C(Cl)=N/O</smiles>

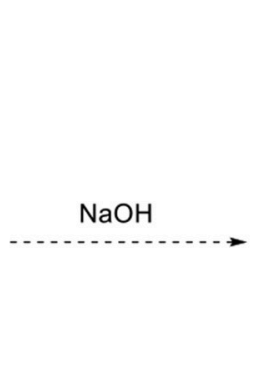

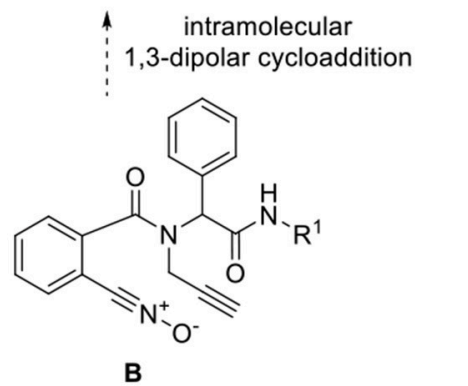

SCHEME $\mathbf{1 0}$ | Synthesis of isoxazolino-benzazepines $\mathbf{2 2 b}$ and isoxazolo-benzazepines $\mathbf{2 2 d .}$ 

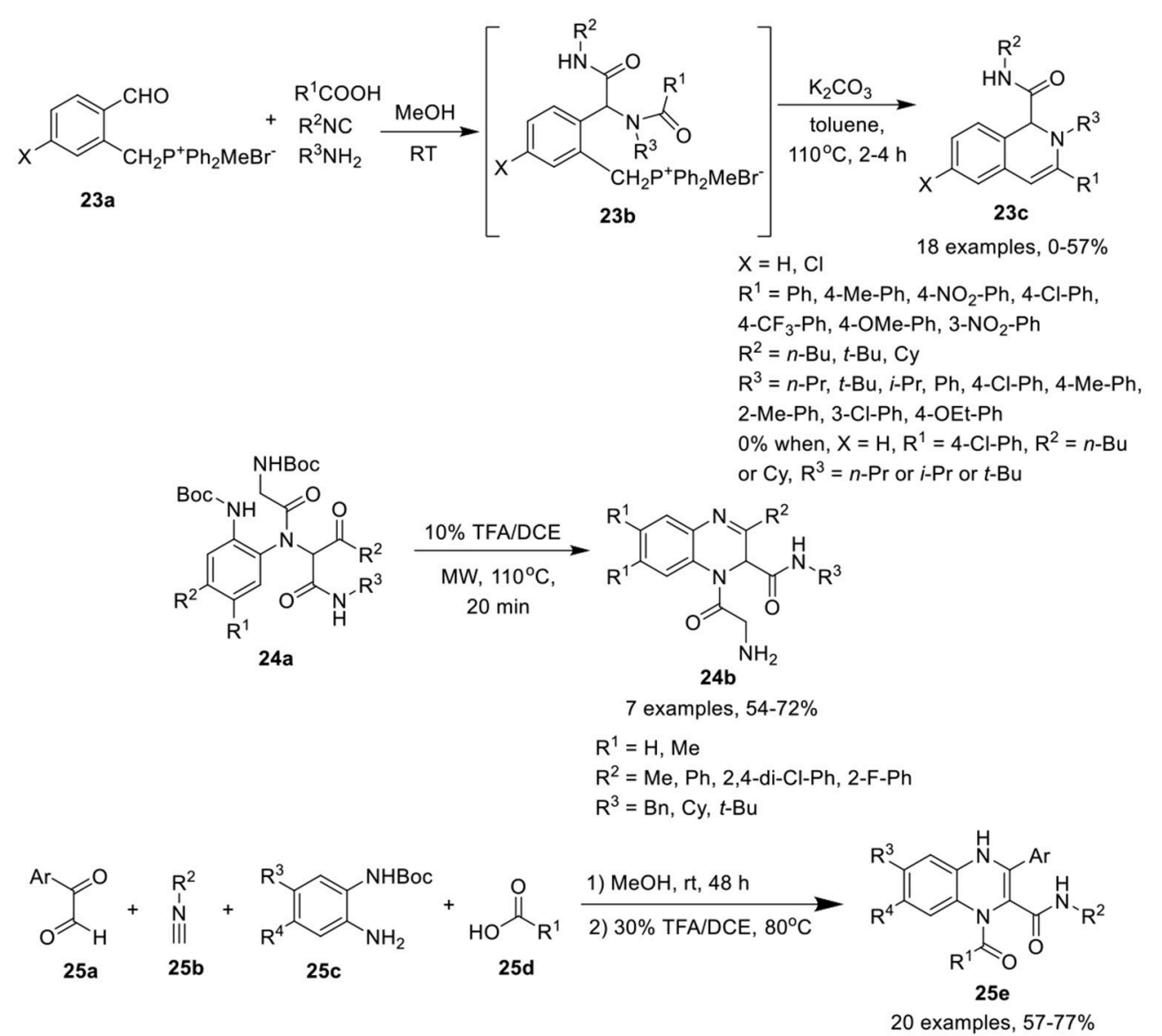

\footnotetext{
$\mathrm{R}^{1}=\mathrm{Me}, \mathrm{Et}, \mathrm{Ph}, c-$ Pro, tetrahydrofuran-2-yl, pyridine-3-yl, Bn

$\mathrm{R}^{2}=\mathrm{Bn}, \mathrm{Cy}, \mathrm{t}-\mathrm{Bu}$

$\mathrm{Ar}=\mathrm{Ph}, 4-\mathrm{OMe}-\mathrm{Ph}, 3-\mathrm{OMe}-\mathrm{Ph}$, etc.

$\mathrm{R}^{3}, \mathrm{R}^{4}=\mathrm{H}, \mathrm{Me}$
}

SCHEME 11 | Synthesis of 1,2-dihydroisoquinolines 23c, quinoxalines $\mathbf{2 4 b}$ and quinoxalines $\mathbf{2 5 e .}$

phosphonium salt 23a underwent intramolecular Wittig reaction in the presence of $\mathrm{K}_{2} \mathrm{CO}_{3}$ in toluene under reflux conditions (Scheme 11). The reaction proceeded smoothly when formic acid or aromatic acids were utilized as acid components. Bulky substituent derived from $t$-butyl isonitrile and aromatic amines were well tolerated under the optimized conditions. However, adducts derived from aliphatic amines failed to afford the desired products. The substituents on the phosphonium salt $\mathbf{2 3}$ b did not influence the product yield.

Chen et al. ( $\mathrm{Li}$ et al., 2017) have utilized a facile Ugi/deprotection/cyclization (UDC) strategy, followed by a nucleophilic aromatic substitution reaction to give access to diverse quinoxalines $\mathbf{2 4 b}$ in moderate to good yields under MW irradiation (Scheme 11). The reaction proceeded smoothly using diversely substituted Ugi-adducts, providing good yields by deprotection and cyclization of Ugi-adducts 24a using TFA in DCE under MW irradiation at $110^{\circ} \mathrm{C}$. Ugi-adducts derived from differently substituted diamines, isonitriles and aromatic aldehydes were found to be well tolerated under the optimized conditions.

Sotelo et al. (Azuaje et al., 2014) have developed a concise one-pot Ugi-based approach to access the quinoxalines $25 \mathbf{e}$ in excellent yields by Ugi-4CR of glyoxals 25a, isocyanides $25 \mathbf{b}$, mono-Boc protected phenylenediamines 25c, and acids $25 \mathrm{~d}$ in methanol at rt, followed by Boc-removal using 30\% TFA/DCE at $80^{\circ} \mathrm{C}$, and subsequent cyclization (Scheme 11). A variety of substituents on all the four building blocks for the Ugi reaction were well tolerated. Bulky substituents on carboxylic acids or isocyanides afforded high yields. However, substitution on the mono-Boc protected phenylenediamines slightly reduced the yield. Further, aromatic acids were better tolerated than aliphatic acids.

\section{Seven-Membered Heterocycles Fused With Six-Membered Carbocyclic Systems}

Dai et al. (Shi et al., 2016) have developed an efficient MWassisted intramolecular Ullmann etherification of Ugi-adducts 
26a and 26c using CuI alone or in combination with $N, N$ dimethylglycine $\mathrm{HCl}(\mathrm{DMG} \cdot \mathrm{HCl})$ as catalyst, in the presence of $\mathrm{Cs}_{2} \mathrm{CO}_{3}$ in dioxane, to give access dibenz $[b, f][1,4]$ oxazepin$11(10 H)$ ones 26b and dibenz $[b, f][1,4]$ oxazepin-11(10H)carboxamides 26d in good to excellent yields and with excellent chemoselectivity (Scheme 12). Under the optimized conditions, most of the reactions proceed smoothly in the absence of ligand under MW irradiation, whereas addition of DMG.HCl as a ligand improves the product yields significantly. Substrates derived from bulky anilines such as 2-naphthylamine, were well tolerated and afforded high product yields. Importantly, for thienyl containing Ugi-adducts, addition of DMG.HCl as ligand was found essential to access the corresponding product. The reaction exhibited excellent chemoselectivity under MW irradiation at elevated temperature. Ugi substrate derived from variety of amines, isocyanides, aldehydes and acids were found well tolerated, providing the products in excellent yields. Interestingly, under these reaction conditions, preference for intramolecular Ullmann etherification was observed over intramolecular Goldberg amidation.

Sharma et al. (Singh et al., 2018) have reported a catalystcontrolled selective intramolecular 7-endo-dig and 6-exodig post-Ugi cyclization of Ugi-adducts 27 a to afford the benzoxazepinones $\mathbf{2 7 b}$ and benzoxazinones 27 c, respectively, with high regioselectivity. The cyclization of Ugi-product 27a was performed using $\mathrm{Pd}\left(\mathrm{CH}_{3} \mathrm{CN}\right)_{4}\left(\mathrm{BF}_{4}\right)_{2}$ as catalyst in toluene facilitated the formation of benzoxazepinones $27 \mathbf{b}$ in high yields with exclusive 7-endo-dig selectivity. However, switching the catalyst to $5 \mathrm{~mol} \%$ of Echavarren's gold(I) catalyst [JohnPhosAu- $\left(\mathrm{CH}_{3} \mathrm{CN}\right) \mathrm{SbF}_{6}$ in DCE resulted in the preferential formation of benzoxazinones $27 \mathrm{c}$ in high yields with 7-exodig selectivity (Scheme 12). Under the optimized conditions for the formation of benzoxazepinones and benzoxazinones, Ugiadducts derived from various alkynes, isonitriles, aldehydes, and amines underwent the reaction smoothly with high selectivity. Several adducts derived from aldehydes bearing electrondonating or electron-withdrawing substituents underwent the reaction smoothly and yielded the corresponding products in moderate to excellent yields. However, adducts from aldehydes bearing an electron-withdrawing substituent such as cyano, bromo, and bis-amide afforded relatively lower yields for 7 endo dig cyclization. No specific electronic effect was observed for the cyclization of Ugi-adducts derived from different isocyanides and 2-aminophenol and afforded the corresponding benzoxazepinones and benzoxazinones in good to high yields. However, Ugi-adducts derived from phenyl substituted alkynes bearing electron-donating groups afforded the corresponding products in slightly lower yields.

\section{Nine-Membered Heterocycles Fused With Five-Membered Heterocycles}

Van der Eycken et al. (Li et al., 2014a) have reported an efficient gold-catalyzed intramolecular hydroarylation reaction of Ugiadduct 28a for the regioselective construction of the fused nine-membered ring in benzo[ $b]$ pyrrolo[2,1-i] $[1,5]$ diazonin$7(6 \mathrm{H})$-ones $\mathbf{2 8 b}$ in good to excellent yields using $10 \mathrm{~mol} \%$
$\mathrm{Au}\left(\mathrm{PPh}_{3}\right) \mathrm{OTf}$ in $\mathrm{CDCl}_{3}$ at $50^{\circ} \mathrm{C}$ (Scheme 12). Under the optimized reaction conditions, Ugi-adducts derived from diversely substituted alkynes, isocyanides, aldehydes, and amines were found compatible and underwent the intramolecular hydroarylation reaction smoothly, providing access to the corresponding benzo[b]pyrrolo[2,1-i] $[1,5]$ diazonin-7 $(6 H)$-ones 28b in good yields. Ugi-adducts from bulky phenyl-substituted alkynes or terminal alkynes afforded moderate product yields. Cyclization of the Ugi-adduct bearing an indole moiety (from aldehyde component) resulted in decomposition of the Ugi-adduct.

\section{Tricyclic Fused Heterocycles}

Jida et al. (Barlow et al., 2016) have developed an efficient, diversity-oriented, one-pot approach to access aminobenzotriazolodiazocine-bearing dipeptides 29c in good to high yields and with good diastereoselectivity. This catalystfree reaction of an azidoaniline 29a, an isocyanide, an aldehyde and a Boc-propargylglycine $29 \mathrm{~b}$, proceeded well in methanol at $\mathrm{rt}$ and was followed by a thermal azide-alkyne Huisgen cycloaddition reaction at $70^{\circ} \mathrm{C}$ (Scheme 13). Variedly substituted azidoanilines were well tolerated and afforded the corresponding products in good yields without any influence on the diastereoselectivity. Aldehydes were preferred over ketones under the optimum conditions for Ugi reaction. Among differently substituted isocyanides, $t$-Bu-substituted isocyanides yielded the corresponding products in $24 \mathrm{~h}$. However, benzyland cyclohexyl-substituted isocyanides required extended reaction times for completion of the reaction. An isomer $29 \mathbf{f}$ with different triazole orientation was obtained in high yield when Boc- $\beta$-azido- $L$-alanine 29e and commercially available ethynyl aniline 29d were used in place of the functionalized azidoanilines 29a and Boc- $L$-propargylamine $\mathbf{2 9 b}$.

Balalaie et al. (Balalaie et al., 2017c) have reported an expedient synthesis of pyranoquinolines $30 \mathbf{b}$ via $\mathrm{InCl}_{3}$-catalyzed post-Ugi intramolecular hydroamidation of alkyne containing Ugi-adduct 30a in toluene at $100^{\circ} \mathrm{C}$ (Scheme 13). The reaction proceeded smoothly under the optimized conditions and accommodated a wide range of Ugi-adducts irrespective of the positional and electronic influence of the substituents, providing the pyranoquinolines in good to excellent yields. The reaction proceeded via $\pi$-activation of the triple bond using $\mathrm{InCl}_{3}$ and delivered intermediate $\mathbf{A}$. The 6-exo-dig that led to the pyran ring was preferred over the 7-endo-dig cyclization (that should result in the oxepine ring). Nucleophilic addition of the amide oxygen to the internal carbon of the triple bond led to the formation of the desired product through intermediate $\mathbf{B}$.

\section{SPIRO-POLYHETEROCYCLES}

Ghandi et al. (2015) have developed a one-pot Ugi metal-free intramolecular bisannulation reaction of 2-chloroquinoline3-carbaldehydes 31a, with amines 31b, acids 31d, or 31e and isocyanide $31 \mathrm{c}$ to give access to spiro[isoindoline-1, $3^{\prime}$ -

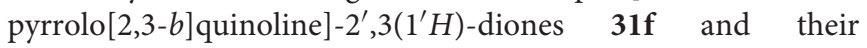
aza-analogs, spiro[pyrrolo[2,3-b]quinoline-3,7' -pyrrolo[3,4$b$ ]pyridine]-2,5' $\left(1 H, 6^{\prime} H\right)$-diones $\mathbf{3 1 g}$, in good to high yields, 


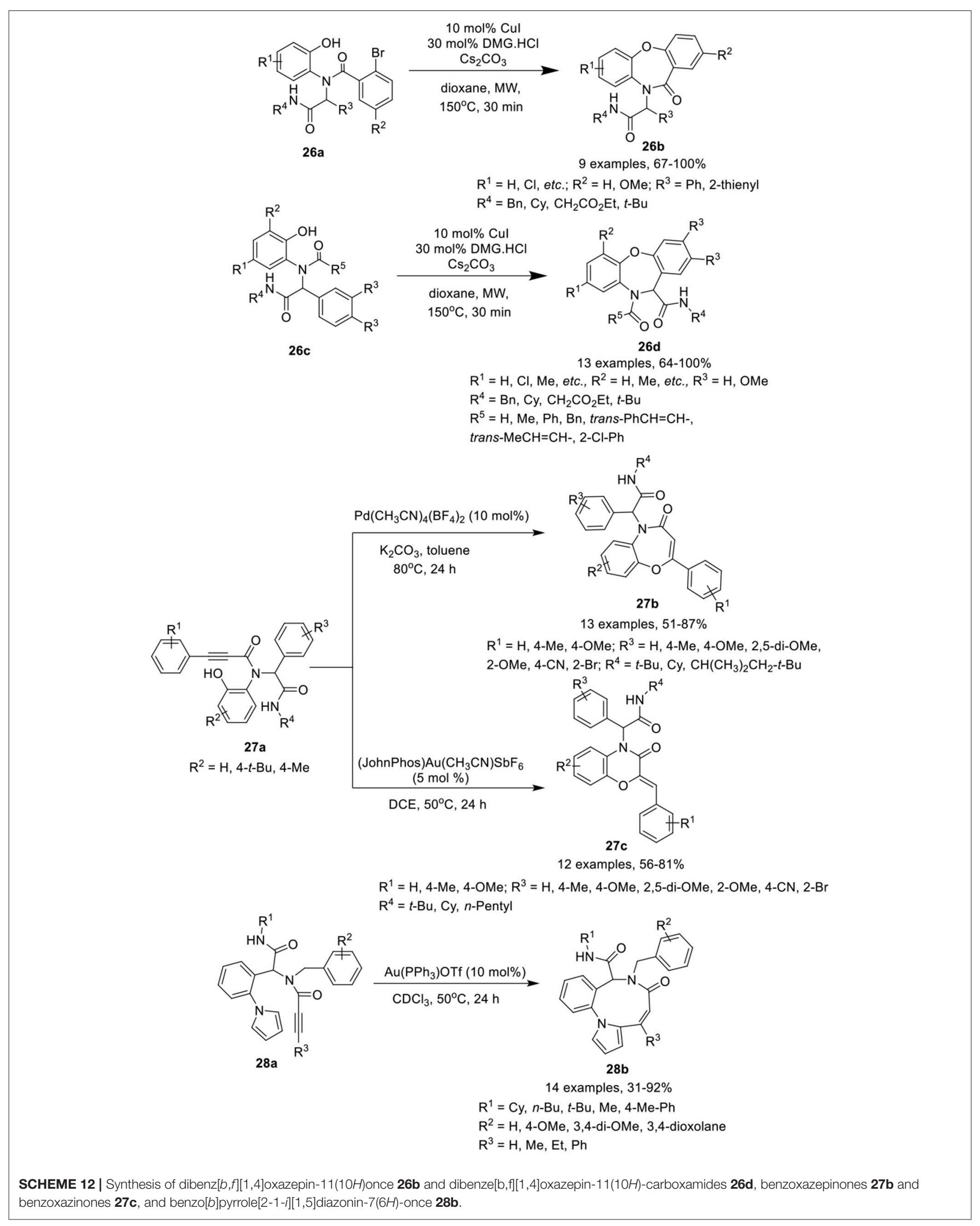




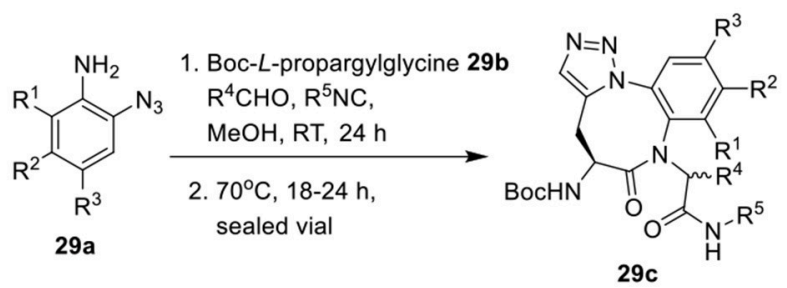

14 examples, $64-82 \%$,

dr. $57 / 43$ to $41 / 59$

$\mathrm{R}^{1}=\mathrm{H}, \mathrm{Me} ; \mathrm{R}^{2}=\mathrm{H}, \mathrm{Br}$, OMe, Ac; $\mathrm{R}^{3}=\mathrm{H}, \mathrm{Br}, \mathrm{OMe}, \mathrm{Ac}$

$\mathrm{R}^{4}=\mathrm{H}, \mathrm{Me}, \mathrm{Bn}, i-\mathrm{Bu}, 4-\mathrm{F}-\mathrm{Ph} ; \mathrm{R}^{5}=t-\mathrm{Bu}, \mathrm{Bn}, \mathrm{Cy}$
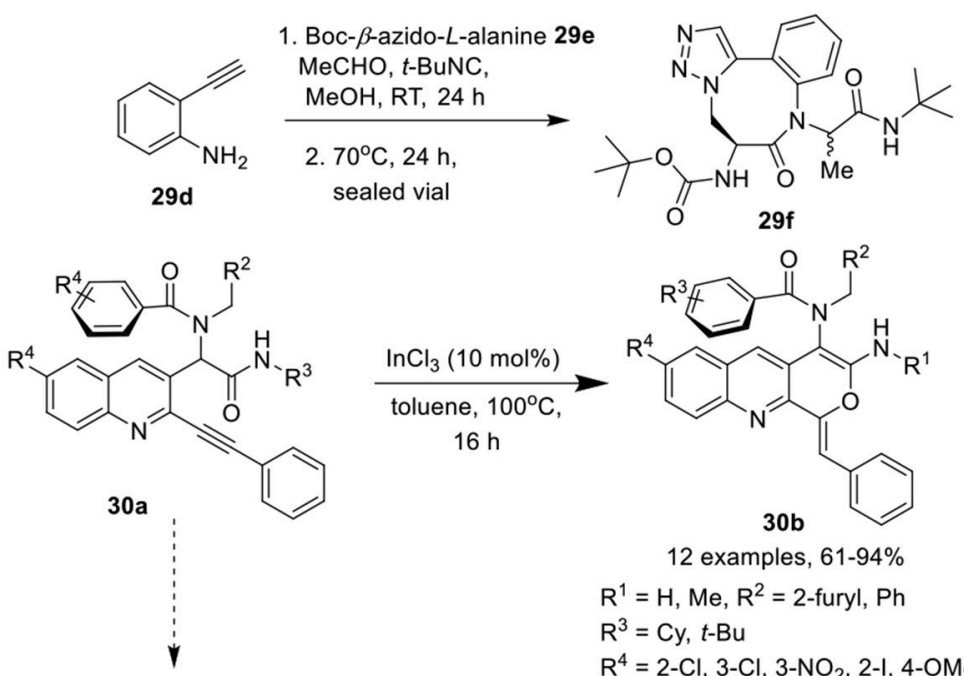

12 examples, $61-94 \%$

$\mathrm{R}^{1}=\mathrm{H}, \mathrm{Me}, \mathrm{R}^{2}=$ 2-furyl, $\mathrm{Ph}$

$\mathrm{R}^{3}=\mathrm{Cy}, \mathrm{t}-\mathrm{Bu}$

$\mathrm{R}^{4}=2-\mathrm{Cl}, 3-\mathrm{Cl}, 3-\mathrm{NO}_{2}, 2-\mathrm{I}, 4-\mathrm{OMe}, 3-\mathrm{OMe}$

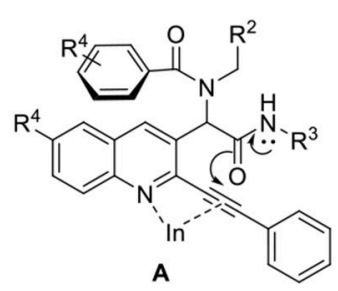

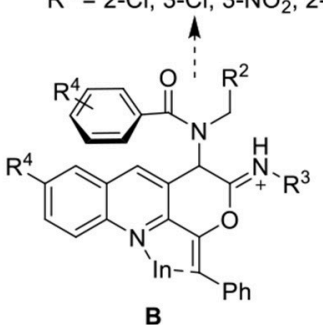

SCHEME 13 | Synthesis of amino-benzotriazocine-bearing dipeptides 29c, 29f and tricyclic pyranoquinolines 30b.

using $\mathrm{Cs}_{2} \mathrm{CO}_{3}$ as base in DMF at $120^{\circ} \mathrm{C}$ for $2 \mathrm{~h}$ (Scheme 14). Under the optimized conditions, adducts derived from aliphatic amines provided access to the corresponding products in high yields compared to aromatic amines. Easy cyclization in high yields was achieved for sterically hindered amides, such as 2,4,4-trimethylpentyl amide, suggested insensitive of the reaction to steric hindrance around the amide. Among the aldehydes, unsubstituted or modest electron-donating methyl substituted aldehydes resulted in higher product yields, compared to aldehydes bearing a stronger electron-donating methoxy group. The present approach is very attractive providing molecular diversity and synthetic simplicity with high atom economy.

Sharma et al. (Li et al., 2016) have reported an efficient and diversity-oriented ligand-controlled intramolecular palladiumcatalyzed domino post-Ugi Buchwald-Hartwig/Aldol reaction sequence for the construction of (spiro)polyheterocycles 32b and 32c using $\mathrm{Pd}(\mathrm{OAc})_{2}$ as catalyst and XantPhos or BINAP as ligand under basic conditions of $\mathrm{Cs}_{2} \mathrm{CO}_{3}$ in toluene at $120^{\circ} \mathrm{C}$ (Scheme 14). A variety of Ugi-adducts 32a derived from 2 -acetyl benzoic acid, afforded the spiro[indoline-3,3'isoquinoline]-diones $\mathbf{3 2} \mathbf{b}$ in modest to excellent yields and with moderate diastereoselectivity. Diversely substituted aromatic aldehydes bearing electron-donating or electron-withdrawing groups were well tolerated. Particularly, fluorine substitution at the $o$ - or $m$-position of the aldehydes yielded the corresponding products with good diastereoselectivity. A bulky substituent such as a tert-butyl amide on the Ugi-adduct has a significant effect on the reaction outcome, resulting in the formation of polycyclic $32 \mathrm{c}$ as a side product. Interestingly, a switch of ligand from XantPhos to BINAP resulted in the regioselective synthesis of tetrahydrobenzofuro-isoquinoline $32 \mathrm{c}$ in high yields, using a mixture of toluene and methanol (1.95: $0.05 \mathrm{~mL})$ 


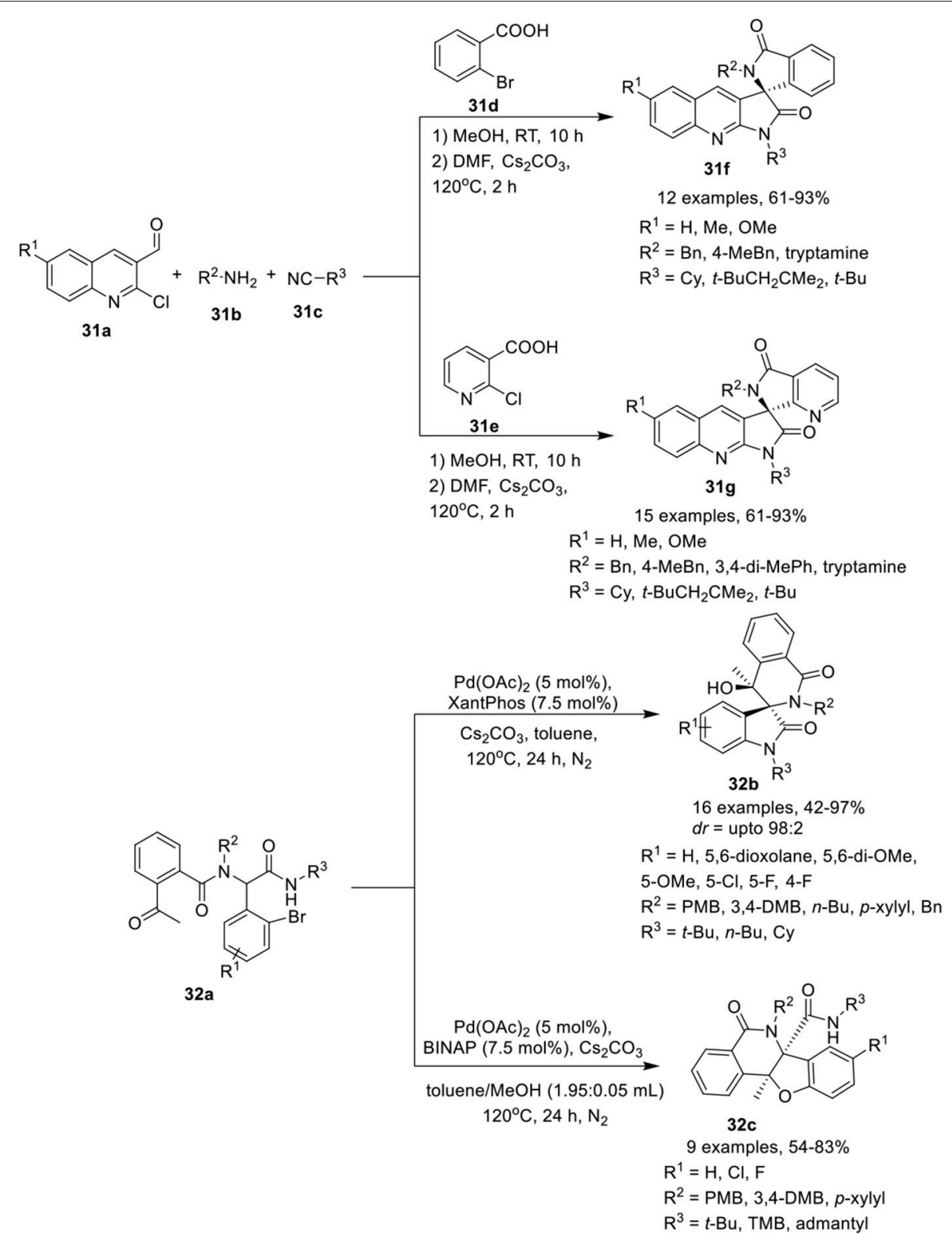

SCHEME 14 | Synthesis of spiropyrroloquinoline-isolinone $\mathbf{3 1 f}$ and their aza-azalogs $\mathbf{3 1 g}$ and (spiro)polyheterocycles $\mathbf{3 2 b}$ and $\mathbf{3 2 c .}$

at $120^{\circ} \mathrm{C}$. Interestingly, regioselective cyclization for this reaction was only observed with a bulky secondary amide group bearing a tert-butyl, a 1,1,3,3-tetramethyl butyl or an adamantyl group. However, linear and cyclic amides led to the formation of a mixture of spirocyclic and polycyclic products.

Sharma et al. (2014) have reported a facile post-Ugi domino Buchwald-Hartwig/Michael reaction of Ugi-adduct 33a to give access to functionalized spiro[indoline- $3,2^{\prime}$-pyrrole]-2,5'-diones $33 \mathbf{b}$ in low to excellent yields using $\mathrm{Pd}(\mathrm{OAc})_{2}$ (5 mol \%) as catalyst, Xantphos $(7.5 \mathrm{~mol} \%)$ as ligand, and $\mathrm{Cs}_{2} \mathrm{CO}_{3}$ as base in toluene at $120{ }^{\circ} \mathrm{C}$ (Scheme 15). Halogen substituted aromatic aldehydes have a significant effect on the reaction outcome as the Ugi-adduct derived from $o$-iodo substituted benzaldehyde afforded the product in higher yields than its chloro substituted counterpart. Electron-donating or electronwithdrawing substituents at the $o, m$, or $p$-position of the aryl ring of the aldehydes were well tolerated. The reactions proceeded smoothly with Ugi-adducts obtained from aliphatic isonitriles. However, the use of aromatic isonitriles provided low product yields. Interestingly, Ugi-adducts obtained from propiolic acid did not provided the desired spiro-product. Additionally, use of $\alpha, \beta$-unsaturated acids (instead of 2 -alkynoic acids) resulted in spirooxindoles in good yields with adequate diastereoselectivities. Ugi-adducts derived from differently substituted amines were well tolerated. 
<smiles>[R]CC#CC(=O)N([R])C(C(=O)N[R])c1c([R])cc([R])c([R])c1[R]</smiles><smiles>[R]c1cc2c(c([R])c1[R])C1(C(=O)C(C)=CC1[R])C(=O)N2[R1]</smiles>

20 examples, 0-97\%

$\mathrm{R}^{1}=t$-Bu, Cy, $p$-tolyl, $n$-Bu; $\mathrm{R}^{2}=\mathrm{PMB}, 4-\mathrm{Me}-\mathrm{Bn}, n-\mathrm{Bu}$, 3,4-DMB, Cy, 3.4-dioxole Bn; $\mathrm{R}^{3}=\mathrm{H}, \mathrm{Me}, \mathrm{Et}, \mathrm{Ph}$ $\mathrm{R}^{4}=\mathrm{H}, \mathrm{F}, \mathrm{Br} ; \mathrm{R}^{5}=\mathrm{H}, \mathrm{OMe}, \mathrm{Cl}, \mathrm{F} ; \mathrm{R}^{6}=\mathrm{H}, \mathrm{OMe}$ $0 \%$ when, $R^{1}=C y, R^{2}=3,4-D M B, R^{3}=R^{4}=R^{5}=R^{6}=H$<smiles>CCOC(=O)/C=C/C(=O)N(C(C)c1ccccc1)[C@@]1(C)C(=O)Nc2ccccc21</smiles>

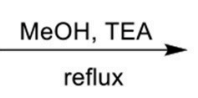<smiles>CCOC(=O)CC1C(=O)N([C@@H](CC)Cc2ccccc2)[C@@]2(C(=O)Nc3ccccc32)C(=O)N1c1ccccc1</smiles>

1 example, $59 \%, 69 \%$ de

SCHEME 15 | Synthesis of spiro[indoline-3,2'-pyrrole]-2,5'-diones 33b and spiro-diketopiperazines 34b.

Silvani et al. (Lesma et al., 2014) have developed an intramolecular aza-Michael reaction for the post-Ugi cyclization of chiral 3,3-disubstituted 3-aminooxindole 34a to access the spiro-diketopiperazine $\mathbf{3 4 b}$ in moderate yield and good diastereoselectivity (Scheme 15). The spiro-diketopiperazine scaffold has received great recognition as pharmacologically active peptidomimetic.

\section{CONCLUSION}

In conclusion, we have demonstrated the wide-spread application of the Ugi reaction for the synthesis of heterocyclic compounds, where careful selection of the starting building blocks provided the appropriate functionality for post-Ugi modifications. We have discussed various recent reports where a variety of heterocyclic systems were successfully synthesized starting from simple four, five or six-membered heterocycles to fused heterocycles and spirocyclized complex molecules. During the post-Ugi transformation, we have witnessed the application of various metallic salts of palladium, gold, indium, copper, zinc, scandium, iron and aluminum, leading to the successful transformation of appropriately substituted Ugi-adducts to heterocyclic systems. The use of modern

\section{REFERENCES}

Ambasana, P. A., Vachhani, D. D., Galli, M., Jacobs, J., Van Meervelt, L., Shah, A. K., et al. (2014). Solvent switchable cycloaddition: a (one-pot) metal-free approach towards $\mathrm{N}$-substituted benzo[e]- or $[f]$ isoindolones via Csp2-H functionalization. Org. Biomol. Chem. 12, 8861-8865. doi: $10.1039 / \mathrm{C} 4 \mathrm{OB} 01644 \mathrm{~K}$ medicinal chemistry tools such as microwave irradiation has also been successfully applied in post-Ugi transformations. Interestingly, the use of chiral ligands such as BINAP, XantPhos, and triphenylphosphine has provided stereoselectivity and chemoselectivity in such transformations. We anticipate that this review would provide in-depth understanding of the chemistry and applications of post-Ugi transformations for the synthesis of variety of heterocyclic systems. New heterocyclic systems with interesting biological activity are expected from the post-Ugi transformation in the near future.

\section{AUTHOR CONTRIBUTIONS}

JB and RK collected the publications related to this review article, wrote the first draft of the manuscript and made subsequent corrections. EV and LV completed critical literature analysis and checked subsequent manuscript drafts.

\section{ACKNOWLEDGMENTS}

We acknowledge the support of Shiva Institute of B. Pharmacy and RUDN University Program 5-100.

Azuaje, J., Maatougui, E. A., Garcia-Mera, X., and Sotelo, E. (2014). Ugibased approaches to quinoxaline libraries. ACS Comb. Sci. 16, 403-411. doi: $10.1021 / \mathrm{CO} 500036 \mathrm{~N}$

Balalaie, S., Kejani, R. R., Ghabraie, E., Darvish, F., Rominger, F., Hamdan, F., et al. (2017a). Diastereoselective synthesis of functionalized diketopiperazines through post-transformational reactions. J. Org. Chem. 82, 12141-12152. doi: 10.1021/acs.joc.7b01855 
Balalaie, S., Mirzaie, S., Nikbakht, A., Hamdan, F., Rominger, F., Navari, R., et al. (2017b). Indium-catalyzed intramolecular hydroamidation of alkynes: an exo-dig cyclization for the synthesis of pyranoquinolines through post-transformational reaction. Org. Lett. 19, 6124-6127. doi: 10.1021 /acs.orglett.7b02603

Balalaie, S., Shamakli, M., Nikbakht, A., Alavijeh, N. S., Rominger, F., Rostamizadeh, S., et al. (2017c). Direct access to isoxazolino and isoxazolo benzazepines from 2-((hydroxyimino)methyl)benzoic acid via a post-Ugi heteroannulation. Org. Biomol. Chem. 15, 5737-5742. doi: $10.1039 / \mathrm{C} 7 \mathrm{OB} 01142 \mathrm{C}$

Bariwal, J. B., Trivedi, J. C., and Van der Eycken, E. V. (2010). "Microwave Irradiation and Multicomponent Reactions," in Synthesis of Heterocycles via Multicomponent Reactions II, eds. R. V. A. Orru and E. Ruijter (Berlin; Heidelberg: Springer Berlin Heidelberg), 169-230.

Barlow, T. M., Jida, M., Guillemyn, K., Tourwe, D., Caveliers, V., and Ballet, S. (2016). Efficient one-pot synthesis of amino-benzotriazolodiazocinone scaffolds via catalyst-free tandem Ugi-Huisgen reactions. Org. Biomol. Chem. 14, 4669-4677. doi: 10.1039/С6ОВ00438E

Biggs-Houck, J. E., Younai, A., and Shaw, J. T. (2010). Recent advances in multicomponent reactions for diversity-oriented synthesis. Curr. Opin. Chem. Biol. 14, 371-382. doi: 10.1016/.j.cbpa.2010.03.003

Ghandi, M., Zarezadeh, N., and Abbasi, A. (2015). One-pot synthesis of spiropyrroloquinoline-isoindolinone and their aza-analogs via the Ugi4CR/metal-free intramolecular bis-annulation process. Org. Biomol. Chem. 13, 8211-8220. doi: 10.1039/С5ОB01095K

Ghoshal, A., Yugandhar, D., Nanubolu, J. B., and Srivastava, A. K. (2017). An efficient one-pot synthesis of densely functionalized fused-quinolines via sequential Ugi4CC and acid-mediated povarov-type reaction. ACS Comb. Sci. 19, 600-608. doi: 10.1021/acscombsci.7b00095

Golubev, P., and Krasavin, M. (2017). Sterically constrained and encumbered: an approach to the naturally occurring peptidomimetic tetrahydropyrazino1,2-a]indole-1,4-dione core. Eur. J. Org. Chem. 2017, 1740-1744. doi: 10.1002/ejoc.201700152

Halimehjani, A. Z., and Sharifi, M. (2017). Synthesis of a novel category of Ugi adducts using succinic acid, succinic anhydride and maleic anhydride and their application in post-Ugi reactions for synthesis of functionalized piperazine 2,5-diones. Tetrahedron 73, 5778-5783. doi: 10.1016/j.tet.2017. 08.028

He, Y., Li, Z., Robeyns, K., Van Meervelt, L., and Van der Eycken, E. V. (2018). A gold-catalyzed domino cyclization enabling rapid construction of diverse polyheterocyclic frameworks. Angew. Chem. Int. Ed. 57, 272-276. doi: 10.1002/anie201710592

He, Y., Li, Z., Tian, G., Song, L., Van Meervelt, L., and Van der Eycken, E. V. (2017). Gold-catalyzed diastereoselective domino dearomatization/ipsocyclization/aza-Michael sequence: a facile access to diverse fused azaspiro tetracyclic scaffolds. Chem. Commun. 53, 6413-6416. doi: $10.1039 /$ C7CC03152A

Hulme, C., and Dietrich, J. (2009). Emerging molecular diversity from the intramolecular Ugi reaction: iterative efficiency in medicinal chemistry. Mol. Divers. 13, 195-207. doi: 10.1007/s11030-009-9111-6

Kaïm, L. E., and Grimaud, L. (2010). Ugi-Smiles couplings: new entries to N-aryl carboxamide derivatives. Mol. Divers. 14, 855-867. doi: $10.1007 /$ s11030-009-9175-3

Kaïm, L. E., and Grimaud, L. (2014). The Ugi-smiles and passerini-smiles couplings: a story about phenols in isocyanide-based multicomponent reactions. Eur. J. Org. Chem. 35, 7749-7762. doi: 10.1002/ejoc.2014 02783

Koopmanschap, G., Ruijter, E., and Orru, R. V. A. (2014). Isocyanidebased multicomponent reactions towards cyclic constrained peptidomimetics. Beilstein J. Org. Chem. 10, 544-598. doi: 10.3762/bjoc.10.50

Lesma, G., Meneghetti, F., Sacchetti, A., Stucchi, M., and Silvani, A. (2014). Asymmetric Ugi 3CR on isatin-derived ketimine: synthesis of chiral 3,3disubstituted 3-aminooxindole derivatives. Beilstein J. Org. Chem. 10, 1383-1389. doi: 10.3762/BJOC.10.141

Li, Y., Lei, J., Xu, J., Tang, D., Chen, Z., Zhu, J., et al. (2017). A facile method for building fused quinoxaline-quinolinones via an acidless post-Ugi cascade reaction. Chinese Chem Lett. 28, 541-545. doi: 10.1016/j.cclet.2016. 10.027
Li, Z., Kumar, A., Sharma, S. K., Parmar, V. S., and Van der Eycken, E. V. (2015a). Catalyst-controlled exo/endo selectivity in a postUgi intramolecular hydroarylation: synthesis of pyrrolopyridinones, pyrroloazepinones, and benzothienopyridines. Tetrahedron 71, 3333-3342. doi: 10.1016/j.tet.2015.03.103

Li, Z., Kumar, A., Vachhani, D. D., Sharma, S. K., Parmar, V. S., and Van der Eycken, E. V. (2014a). Regioselective synthesis of diversely substituted diazoninones through a post-Ugi gold-catalyzed intramolecular hydroarylation process. Eur. J. Org. Chem. 2014, 2084-2091. doi: 10.1002/ejoc.201301507

Li, Z., Legras, L., Kumar, A., Vachhani, D. D., Sharma, S. K., Parmar, V. S., et al. (2014b). Microwave-assisted synthesis of $4 H$-benzo[f]imidazo[1,4]diazepin6-ones via a post-Ugi copper-catalyzed intramolecular Ullmann coupling. Tetrahedron Lett. 55, 2070-2074. doi: 10.1016/j.tetlet.2014.02.023

Li, Z., Sharma, N., Sharma, U. K., Jacobs, J., Van Meervelt, L., and Van der Eycken, E. V. (2016). Ligand-controlled product selectivity in palladium-catalyzed domino post-Ugi construction of (spiro)polyheterocycles. Chem. Commun. 52, 5516-5519. doi: 10.1039/C6CC00784H

Li, Z., Sharma, U. K., Liu, Z., Sharma, N., Harvey, J. N., and Van der Eycken, E. V. (2015b). Diversity-oriented synthesis of $\beta$-lactams and $\gamma$-lactams by Post-Ugi nucleophilic cyclization: lewis acids as regioselective switch. Eur. J. Org. Chem. 2015, 3957-3962. doi: 10.1002/ejoc.201500270

Madhavachary, R., Zarganes-Tzitzikas, T., Patil, P., Kurpiewska, K., KalinowskaTluscik, J., and Dömling, A. (2018). Synthesis of highly substituted imidazole uracil containing molecules via Ugi-4CR and passerini-3CR. ACS Comb. Sci. 20, 192-196. doi: 10.1021/acscombsci.7b00145

Medda, F., Martinez-Ariza, G., and Hulme, C. (2015). A facile and concise route toward the synthesis of novel imidazo-tetrazolodiazepinones via postcondensation modifications of the Ugi-azide adduct. Tetrahedron Lett. 56, 5295-5298. doi: 10.1016/j.tetlet.2015.07.083

Ramon, D. J., and Yus, M. (2005). Asymmetric multicomponent reactions (AMCRs): the new frontier. Angew. Chem. Int. Ed. Engl. 44, 1602-1634. doi: $10.1002 /$ anie. 200460548

Sagar, A., Babu, V. N., and Sharada, D. S. (2015). Silica gel promoted environmentfriendly synthesis of $\alpha$-amino amidines and regioselective transformation of $\alpha$ amino amidines into amidino substituted indazoles. RSC Adv. 5, 29066-29071. doi: 10.1039/C5RA02491A

Sharma, N., Li, Z., Sharma, U. K., and Van der Eycken, E. V. (2014). Facile access to functionalized spiro[indoline-3, $2^{\prime}$-pyrrole]-2, $5^{\prime}$-diones via postUgi domino Buchwald-Hartwig/Michael reaction. Org. Lett. 16, 3884-3887. doi: 10.1021/Ol5019079

Sharma, U. K., Sharma, N., Vachhani, D. D., and Van der Eycken, E. V. (2015). Metal-mediated post-Ugi transformations for the construction of diverse heterocyclic scaffolds. Chem. Soc. Rev. 44, 1836-1860. doi: 10.1039/C4CS00253A

Shi, J., Wu, J., Cui, C., and Dai, W. (2016). Microwave-Assisted intramolecular ullmann diaryl etherification as the post-ugi annulation for generation of dibenz $[b, f][1,4]$ oxazepine Scaffold. J. Org. Chem. 81, 10392-10403. doi: $10.1021 /$ acs.joc.6b01398

Shiri, M., Mirpour-Marzoni, S. Z., Bozorgpour-Savadjani, Z., Soleymanifard, B., and Kruger, H. G. (2014). Base-catalyzed cyclization of Ugi-adducts to substituted indolyl based $\gamma$-lactams. Monatsh Chem. 145, 1947-1952. doi: 10.1007/s00706-014-1271-0

Singh, K., Malviya, B. K., Roy, T. K., Mithu, V. S., Bhardwaj, V. K., Verma, V. P., et al. (2018). Catalyst-controlled structural divergence: selective intramolecular 7-endo-dig and 6-exo-dig Post-Ugi cyclization for the synthesis of benzoxazepinones and benzoxazinones. J. Org. Chem. 83, 57-68. doi: $10.1021 /$ acs.joc.7b02123

Srinivasulu, V., Sieburth, S. M., El-Awady, R., Kariem, N. M., Tarazi, H., O'Connor, M. J., et al. (2018). Post-Ugi cascade transformations for accessing diverse chromenopyrrole collections. Org. Lett. 20, 836-839. doi: 10.1021/acs.orglett.7b03986

Trang, T. T. T., Peshkov, A. A., Jacobs, J., Van Meervelt, L., Peshkov, V. A., and Van der Eycken, E. V. (2015). Post-Ugi carbocyclization/fragmentation sequence for the synthesis of 6,7-dihydro-5H-pyrrolo3,4-b]pyridin-5-ones. Tetrahedron Lett. 56, 2882-2886. doi: 10.1016/j.tetlet.2015.03.092

Ugi, I. (1962). The $\alpha$-addition of immonium ions and anions to isonitriles accompanied by secondary reactions. Angew. Chem. Int. Ed. Engl. 1, 8-21. doi: $10.1002 /$ anie. 196200081 
Ugi, I., and Steinbrückner, C. (1961). Isonitrile, II. Reaktion von Isonitrilen mit Carbonylverbindungen, Aminen und Stickstoffwasserstoffsäure. Chem. Ber. 94, 734-742. doi: $10.1002 /$ cber. 19610940323

Vachhani, D. D., Kumar, A., Modha, S. G., Sharma, S. K., Parmar, V. S., and Van der Eycken, E. V. (2015). Diversely substituted indoloazepinones and indoloazocinones: a post-ugi gold-catalyzed regioselective carbocyclization approach. Synthesis 47, 1337-1347. doi: 10.1055/s-0034-1379894

VenkataPrasad, J., Krishnamurthy, S., Moriguchi, T., and Tsuge, A. (2017). Efficient synthesis of novel pyrrolo2,3-c]pyridone derivatives using the Ugi four-component reaction followed by condensation reaction. New J. Chem. 41, 97-107. doi: 10.1039/C6NJ02569B

Wang, L., Guan, Z., and Ding, M. (2016). One-pot synthesis of $1 \mathrm{H}$ isochromenes and 1,2-dihydroisoquinolines by a sequential isocyanidebased multicomponent/Wittig reaction. Org. Biomol. Chem. 14, 2413-2420. doi: 10.1039/C5OB02405F

Xiuming, L., Xueshun, J., and Liang, Y. (2017). Recent progress on post-Ugi reaction. Chin. J. Org. Chem. 37, 2237-2249. doi: 10.6023/cjoc201704026
Zamudio-Medina, A., Garca-González, M. C., Gutierrez-Carrillo, A., and González-Zamora, E. (2015). Synthesis of cyclic analogues of hexamethylenebis(3-pyridine)amide (HMBPA) in a one-pot process. Tetrahedron Lett. 56, 627-629. doi: 10.1016/j.tetlet.2014. 12.018

Conflict of Interest Statement: The authors declare that the research was conducted in the absence of any commercial or financial relationships that could be construed as a potential conflict of interest.

Copyright $\odot 2018$ Bariwal, Kaur, Voskressensky and Van der Eycken. This is an open-access article distributed under the terms of the Creative Commons Attribution License (CC BY). The use, distribution or reproduction in other forums is permitted, provided the original author(s) and the copyright owner(s) are credited and that the original publication in this journal is cited, in accordance with accepted academic practice. No use, distribution or reproduction is permitted which does not comply with these terms. 